Article

\title{
An Intelligent Approach to Active and Reactive Power Control in a Grid-Connected Solar Photovoltaic System
}

\author{
Ibrahim Alsaidan ${ }^{1}\left(\mathbb{C}\right.$, Priyanka Chaudhary ${ }^{2,3, *}$, Muhannad Alaraj ${ }^{1}\left[\right.$ and Mohammad Rizwan ${ }^{1,2}$ (i) \\ 1 Department of Electrical Engineering, College of Engineering, Qassim University, Buraydah 52571, \\ Qassim, Saudi Arabia; Alsaidan@qu.edu.sa (I.A.); Muhannad@qu.edu.sa (M.A.); MR.Khan@qu.edu.sa (M.R.) \\ 2 Department of Electrical Engineering, Delhi Technological University, Delhi 110042, India \\ 3 Department of Electrical Engineering, SET, Noida International University, Noida 203201, India \\ * Correspondence: priyankach.iilm@gmail.com
}

\section{check for} updates

Citation: Alsaidan, I.; Chaudhary, P.; Alaraj, M.; Rizwan, M. An Intelligent Approach to Active and Reactive Power Control in a Grid-Connected Solar Photovoltaic System.

Sustainability 2021, 13, 4219.

https://doi.org/10.3390/su13084219

Academic Editors: M.

Dolores Esteban,

José-Santos López-Gutiérrez and Vicente Negro

Received: 6 March 2021

Accepted: 30 March 2021

Published: 10 April 2021

Publisher's Note: MDPI stays neutral with regard to jurisdictional claims in published maps and institutional affiliations.

Copyright: (c) 2021 by the authors. Licensee MDPI, Basel, Switzerland. This article is an open access article distributed under the terms and conditions of the Creative Commons Attribution (CC BY) license (https:/ / creativecommons.org/licenses/by/ $4.0 /)$.

\begin{abstract}
The increasing demand of electrical energy and environmental concerns are invigorating the use of renewable energy resources for power generation. Renewable energy resources can provide an attractive solution for present and future energy requirements. In this scenario, solar photovoltaic systems are becoming prominent and sustainable solutions with numerous advantages. However, the utilization of solar photovoltaic systems in distribution generation makes it mandatory to deploy efficient and organized control measures for integrating solar photovoltaic plants with the grid. In this paper, the control of grid-tied solar photovoltaic systems using a Kalman filterbased generalized neural network is presented with a variable step size perturb and observe-based maximum power point tracking controller to extract the maximum power from a solar photovoltaic plant. The presented system provides power-quality enhancement and supports a three-phase AC grid. The proposed approach extracts the load currents' primary components for efficient harmonics elimination, synchronizes the system with the grid and provides a fast response during rapidly changing conditions. The results of the proposed control technique are also compared with the artificial neural network-based control technique for validation purposes. The proposed algorithm is found more suitable for using a smaller number of unknown weights and training patterns with reduced computational time.
\end{abstract}

Keywords: renewable energy resources; grid integrated solar PV systems; sustainable power generation; maximum power point tracking; grid reliability and voltage source converter

\section{Introduction}

The increasing concern regarding greenhouse gas emissions and the depleting nature of conventional fuels has invigorated the use of renewable energy resources as an alternative and sustainable solutions for the power sector. Solar, wind, biomass and small hydro power are the main renewable energy-based resources which can fulfill the future energy requirements. The solar photovoltaic system (SPV) is more encouraged due to various advantages such as abundance of availability, less environmental pollution, reduced cost and many others. The progress of an SPV system in the existing power system is witnessed for its progress [1]. The integration of an SPV system into the grid causes positive effects, i.e., generating more power, along with some negative effects, i.e., the violation of voltage limitations at common coupling, frequencies disruption and grid stabilization problems, etc. There are set guidelines, codes and standards for grid-connected SPV systems. These standards include IEEE 1547, IEC 61727 and VDE-AR-N4105 [2]. The use of these standards is encouraged and imposed to maintain the stability and power quality related to the grid. The large-scale exploitation of distributed generation make it mandatory to deploy efficiency and organized control measures for integrating and measuring problems. The control algorithms are helpful for the accommodation and facilitation of the integration of an SPV in the distribution grid. Single-stage and two-stage systems have been used for 
the integration of SPV systems into the grid, as shown in previous works. It has also been shown by various researchers that for a three-phase system, a single-stage configuration is more advantageous [3]. However, conventional single-stage SPV systems suffer from the drawback of converters being idle during the unavailability of power from the SPV system. To overcome the abovementioned problems, the proposed system is designed in such a manner so that it operates as a distribution static compensator (DSTATCOM) while SPV power is not available and restores the operation after recovering the SPV power generation.

The electrical power distribution system has been designed to distribute active power pertaining a smaller number of harmonics to the consumers. DSTATCOM integrated as a shunt compensator with a distribution system effectively controls harmonics, fulfils the demand of reactive power of consumers and improves voltage regulation with balanced and unbalanced loads [4]. The researchers have reported various configurations of DSTAT$\mathrm{COM}$ in the literature [5-8]. For efficiently integrating distributed a generation system that compensates for the reactive power and harmonics for utility grids at common coupling points, several converter topologies [9-11] and control strategies [12-18] were reported in the previous work. Additionally, Jain et al. [19] presented a grid-integrated solar energy conversion setup with a movable direct current link voltage to vary the voltages at common pairing points with two-stage circuitry methodology and an associated double-frequency second-order generalized integrator (DFSOGI)-dependent control strategy for controlling the multi-functional voltage source converter (VSC) in abrupt load modification at common connecting points.

Varma et al. [19] have proposed a solar photovoltaic static compensator for improving the power transfer capabilities of the system to transmit real power to utilities with an existing converter system. Humid et al. [20] proposed a strategy that depends on a power conditioning unit located parallel to the plant that works in feed-forward mode to compensate the distorted current photovoltaic output to decrease the harmonic of current from a PV system. Kannan et al. [21] presented icos $\Phi$ control technique for a distribution static compensator that gives uninterrupted harmonic degradation, compensates re-active power and compensates the loads along with comparing performances of fuzzy-logic controllers to ordinary proportional integral (PI) controllers. Mishra et al. [22] implemented an optimistic control technique which optimizes the proportional integral's coefficients and photovoltaic fed distribution static compensator's filtration parameters.

To enhance the performance of grid the integrated SPV plant, various control techniques were adopted by the researchers. There are some performance indicators such as less computational time, high accuracy and less complexity, etc. A huge number of techniques depending upon artificial neural networks (ANN) have been widely adopted by a large number of journalists for distribution static compensators implementing dynamic loading [23-27], whereas photovoltaic fed distribution static compensator systems have been adopted by very few. Singh et al. [28] presented a grid interfaced SPV generation plant implementing a neural network-based control technique that utilizes the least mean square (LMS) algorithm, termed adaline (adaptive linear element), for estimating the reference source current. Artificial neural network-based approaches are complex and need large computational times. Further, generalized neural network (GNN)-based control strategies can be used to overcome the abovementioned issues. Applications of GNN are widely available in load forecasting, solar irradiance/energy forecasting, load frequency control in power systems, power system stabilizers, electrical machines and control system-related problems [29-36]. There are few works are reported in the literature related to the application of GNN as a control strategy for grid-tied SPV systems. GNN-based models reduce the training time as well as improve the performance of the system. Considering this, a GNN-based control strategy has been developed for a PV DSTATCOM system in the present work.

The converting capability of a solar photovoltaic plant is comparatively small; thus, to increase the capability of solar photovoltaic plants, it is essential to keep a track of the maximum 
power point. Maximum Power Point Tracking (MPPT) is complicated because of the non-linear character of SPV plants due to changing meteorological factors, i.e., solar irradiance, ambient temperature, wind velocity and relative humidity, etc. A lot work has been reported in the literature related to MPPT, including techniques such as perturb and observe, incremental conductance, constant voltage, open-circuit voltage, short-circuit current, extremum seeking control and hybrid, etc. Further, there are a number of intelligent techniques also available for MPPT such as artificial neural networks (ANN), fuzzy logic, genetic algorithms, etc. [37-39]. A changeable step size perturb and observe (P\&O) MPPT technique is utilized in this research to track the MPP of a solar photovoltaic plant.

Further, to improve the performance of the system, an extended Kalman filter (EKF) [40-42]-based method is adopted to estimate and update the weights of the GNN model. The main contributions of this work are:

- $\quad$ Active power feeding to the connected loads and grid with mitigation of power quality issues. A generalized neural network (GNN)-based approach plays the role of primary control strategy and decides the switching pattern of the voltage source converter (VSC).

- Further, the performance of the proposed algorithm has been improved with the help of EKF for GNN weight estimations.

- The performance of the proposed setup is validated using simulation results implemented in the MATLAB / Simulink platform.

- The developed system obtains acceptable limits of harmonics in utility currents and voltage fluctuations according to the IEEE-519 and IEEE-1547 standards.

The developed system functions very well with an EKF GNN-based approach and gives a very fast response. Moreover, single-stage topology is able to reduce the losses in semiconductor devices and increase the overall efficiency. The proposed control approach performs with more flexibility in training the network under dynamic conditions. The proposed technique possesses various advantages such as its speed, using a single layer, less mathematical calculations and easy implementation on hardware.

The organization of paper is as follows: Section 2 provides details about the system configuration, followed by Section 3 which explains the developed control technique. The simulation and hardware results are provided in Section 4. The conclusion is given in Section 5, followed by acknowledgements and references.

\section{System Description}

The proposed system deploys a single-stage circuit topology and consists of a solar PV array, voltage source converter (VSC), ripple filter, loads and a three-phase utility grid, as shown in Figure 1. A solar PV array is a combination of several PV modules in a series and parallel according to the requirements. A PV cell serves as the basic unit for a solar PV module. A single diode solar PV cell is considered for this system, and mathematical modeling is given [43]. The developed system has been implemented with a minimum number of sensors with a variable step size perturb and observe (P\&O) MPPT algorithm to achieve maximum power point operation of the solar PV system for different meteorological parameters. An extended Kalman filter (EKF)-based GNN methodology is used for controlling the VSC switching to synchronize the system with the grid and the main task of separating the weights of the primary real and reactive parts of three-phase load currents to obtain reference grid currents. The developed system design specifications are given below: 


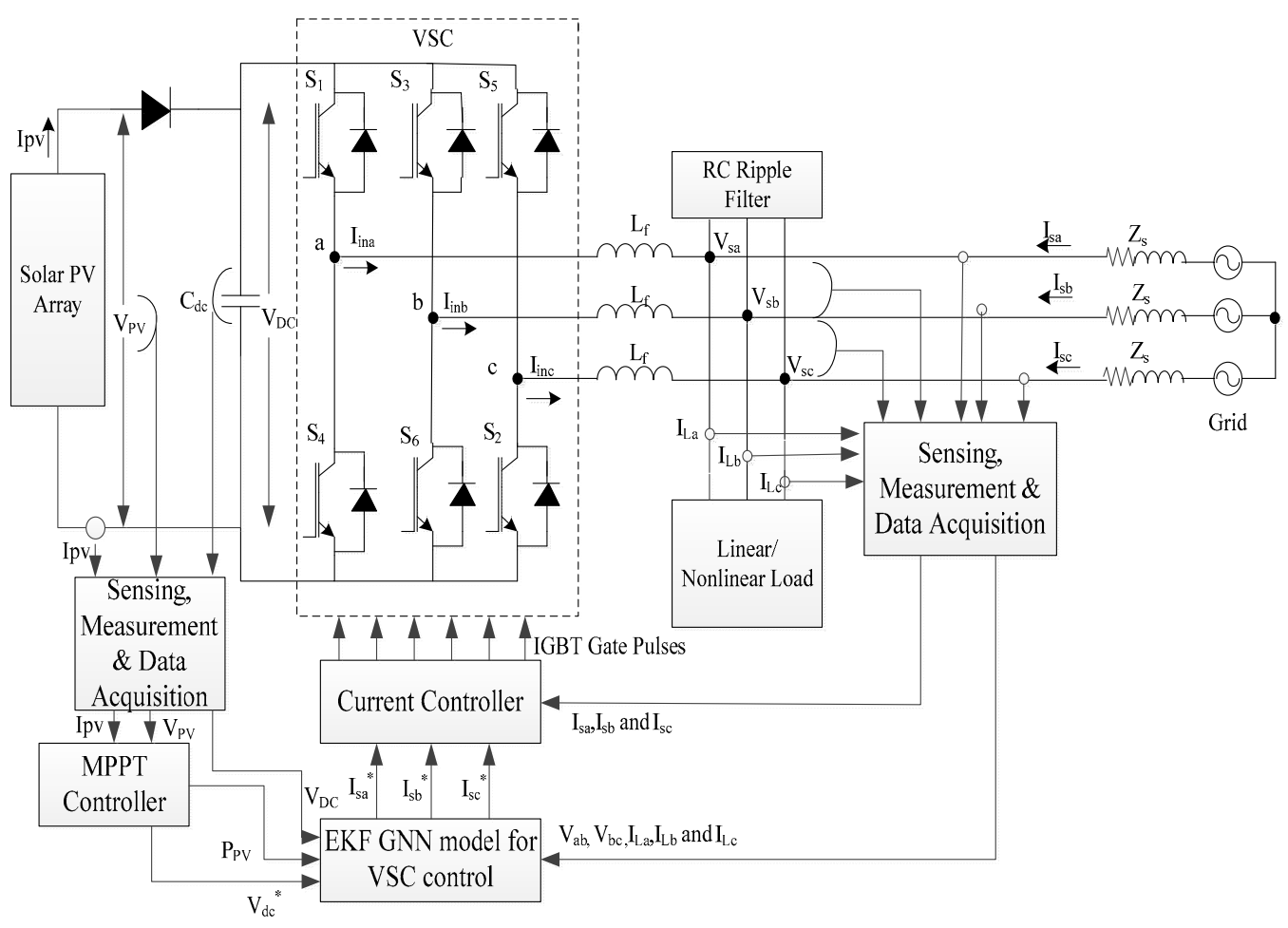

Figure 1. Schematic representation of the system used in this research.

Grid description $=$ three-phase, 415 Volts, $50 \mathrm{~Hz}$, solar $\mathrm{PV}$ array ratings $=\left(\mathrm{V}_{\mathrm{MPP}}\right)=$ 700 Volts, current $(\mathrm{IMPP})=13.5 \mathrm{Amp}$, solar photovoltaic power at maximum power point $(\mathrm{PMPP})=10 \mathrm{~kW}$, rating of interfacing inductors $\left(\mathrm{L}_{\mathrm{fa}}=\mathrm{L}_{\mathrm{fb}}=\mathrm{L}_{\mathrm{fc}}\right)=2.6 \mathrm{mH}$, rating of DC link capacitor $\left(\mathrm{C}_{\mathrm{DC}}\right)=10 \mathrm{mF}, \mathrm{DC}$ link voltage $(\mathrm{VDC})=700 \mathrm{~V}$.

\section{Extended Kalman Filter-Based GNN Control Algorithm}

\subsection{Maximum Power Point Tracking Control}

A variable step size perturb and observe (P\&O)-based MPPT algorithm is employed in this research for the extraction of maximum power from the SPV system. The main operation of the given algorithm is dividing the SPV system's $\mathrm{dP}_{\mathrm{pv}} / \mathrm{dV}_{\mathrm{pv}}$ curve into three independent regions. Region 0 denotes the SPV system power's closeness to the highest power point. Region 0 uses the normal value of tracking step size, whereas region 1 and region 2 needed a larger value of step size as compared to region 0 for achieving the high tracking speed. Figure 2 explains the performed functions of the proposed technique. $\Delta$ Vref0, $\Delta$ Vref1 and $\Delta$ Vref2 represent the step size of tracking for region 0 , region 1 and region 2 , respectively. 


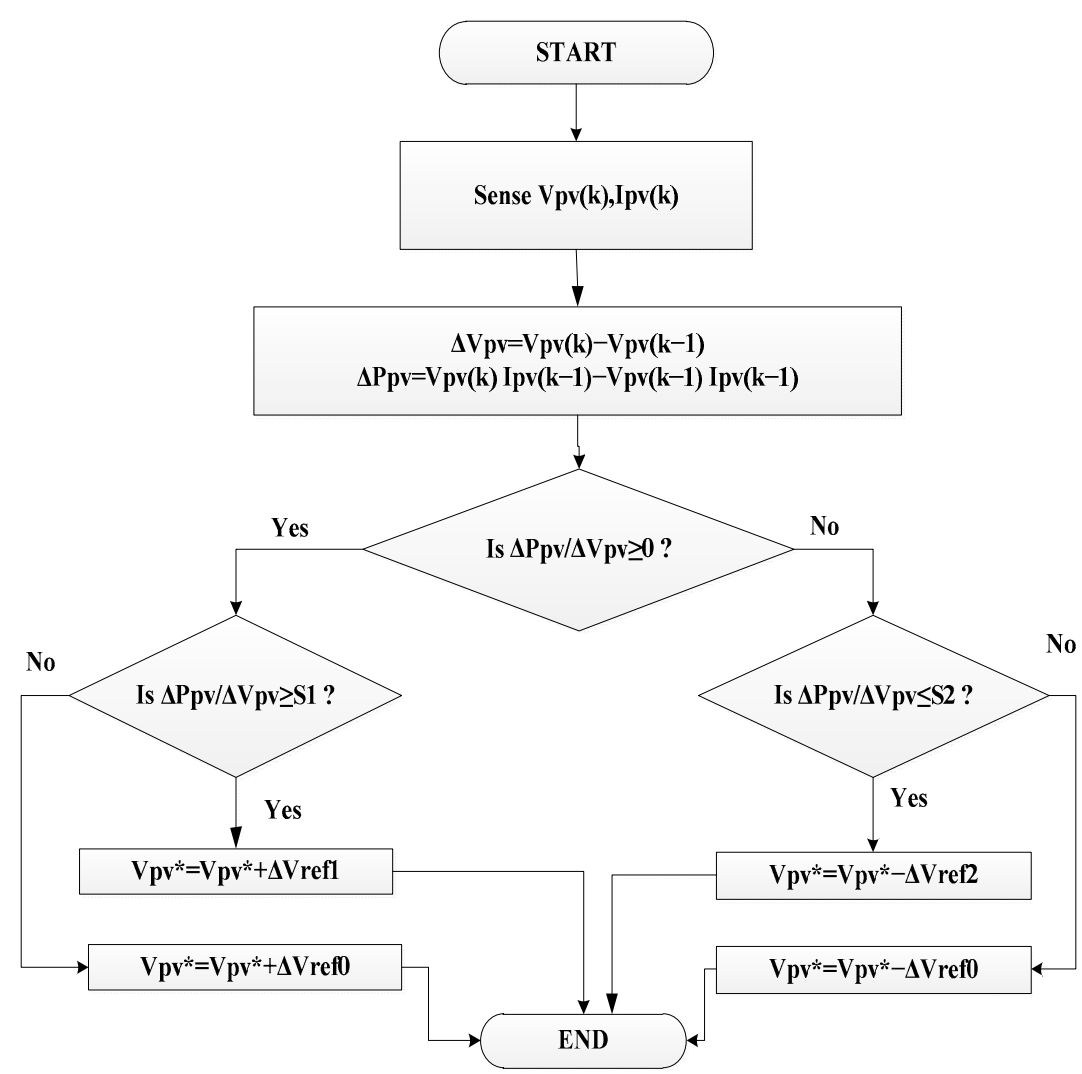

Figure 2. Flowchart of variable step size perturb and observe (P\&O) algorithm.

\subsection{Extended Kalman Filter-Based GNN Control Algorithm}

A generalized neural network works like a multi-layer feed-forward network, where every node implements a precise function on all signals that come to the node, and the parameters are set referring to the node. Figure 3 shows an aggregate-type format of a GNN model, with $\Sigma$ and $\Pi$ being the aggregated functions. $\Sigma$ is an aggregated function, which is adopted with the sigmoidal characteristic function $f_{1}$, whereas the $\Pi$ aggregation function is adopted with the Gaussian function $f_{2}$. The derivation of active and re-active load current components is performed by assuming load current $\left(i_{\mathrm{La}}, \mathrm{i}_{\mathrm{Lb}}, \mathrm{i}_{\mathrm{LC}}\right)$ as the input to the summation $\left(\Sigma_{\mathrm{A}}\right)$ and product $(\Pi)$ neurons having undefined weights of $\left(\mathrm{W}_{\Sigma \mathrm{i}}\right)$ and $\left(\mathrm{W}_{\Pi \mathrm{i}}\right)$, respectively.

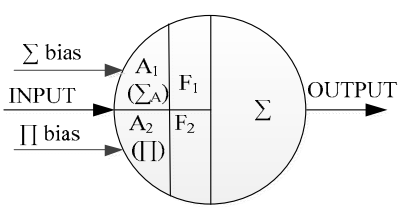

(a)

Figure 3. Cont. 


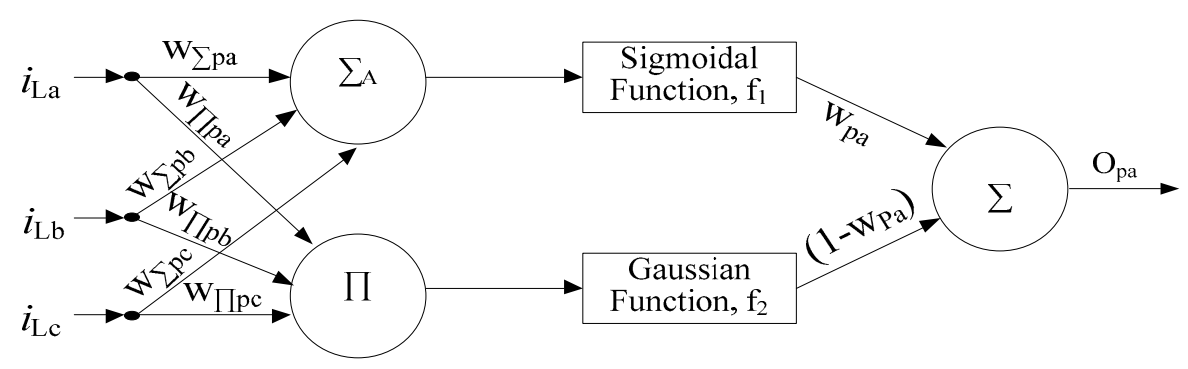

(b)

Figure 3. (a) Summation-type generalized neural network (GNN) model, (b) a summation-type GNN structure to determine the fundamental active element of a load current.

\subsubsection{Estimation of Amplitude of Terminal Voltage and Unit Templates}

With the help of sensed line voltages $\left(v_{a b}, v_{b c}, v_{c a}\right)$ at the point of common coupling (PCC), the amplitude of phase voltages $\left(v_{a}, v_{b}\right.$ and $\left.v_{c}\right)$ are calculated as follows:

$$
v_{a}=\frac{2 v_{a b}+v_{b c}}{3}, v_{b}=\frac{-v_{a b}+v_{b c}}{3}, v_{c}=\frac{-v_{a b}-2 v_{b c}}{3} \Sigma
$$

The terminal voltage amplitude at PCC can be estimated as

$$
\begin{gathered}
V_{t}=\sqrt{\left[\frac{2\left(v_{a}^{2}+v_{b}^{2}+v_{c}^{2}\right)}{3}\right]} \\
u_{p a}=\frac{v_{a}}{V_{t}}, u_{p b}=\frac{v_{b}}{V_{t}}, u_{p c}=\frac{v_{c}}{V_{t}}
\end{gathered}
$$

Further, quadrature unit templates can be calculated using in-phase unit templates as

$$
u_{q a}=\frac{u_{p c}}{\sqrt{3}}-\frac{u_{p b}}{\sqrt{3}}, u_{q b}=\frac{\sqrt{3} u_{p a}}{2}+\frac{u_{p b}-u_{p c}}{2 \sqrt{3}}, u_{q c}=\frac{u_{p b}-u_{p c}}{2 \sqrt{3}}-\frac{\sqrt{3} u_{p a}}{2}
$$

\subsubsection{Terminal Voltage Amplitude and Unit Templates}

The DC link voltage $\left(V_{d c}\right)$ is sensed and compared with the reference DC link voltage $\left(V_{d c}^{*}\right)$ in order to determine the active loss component.

$$
V_{d c e}(k)=V_{d c}^{*}(k)-V_{d c}(k)
$$

$k$ is the number of iterations. Further, the error $\left(V_{d c e}\right)$ of reference $V_{d c}^{*}$ and sensed $V_{d c}$ are processed through a PI controller, the output of which is an active current component $\left(w_{p d c}\right)$ used to regulate the DC link. The controller output at $k^{\text {th }}$ iteration is estimated as

$$
w_{p d}(k)=w_{p d}(k-1)+k_{p d}\left\{V_{d c e}(k)-V_{d c e}(k-1)\right\}+k_{i d} V_{d c e}(k) .
$$

During no sunshine conditions $\left(P_{P V}=0\right)$, the set point DC link voltage is set to reference the DC link voltage of DSTATCOM so that the system operates in the power quality improvement mode (as a DSTATCOM).

The error $V_{t e}$ has been considered between actual and set terminal voltage, $V_{t}$ and $V_{t}^{*}$, at PCC to calculate the reactive loss component. Further, this error is passed through a PI controller for minimization. The calculated reactive loss component is considered to maintain AC terminal voltage constant and close to its reference value.

$$
V_{t e}(k)=V_{t}^{*}(k)-V_{t}(k)
$$


The controller output at $k^{\text {th }}$ instant is

$$
w_{q t}(k)=w_{q t}(k-1)+k_{p t}\left\{V_{t e}(k)-V_{t e}(k-1)\right\}+k_{i t} V_{t e}(k)
$$

where $w_{q t}$ is a part of the reactive loss current component, and $k_{p t}$ and $k_{i t}$ are proportional and integral gains, respectively.

A feed-forward weight is calculated and incorporated into the controller to achieve a fast dynamic response, which can be written as:

$$
w_{P V}(k)=\frac{2 P_{P V}(k)}{3 V_{t}}
$$

where $P_{P V}$ is solar power.

\subsubsection{Fundamental Active and Reactive Component of Load Current}

A generalized neural network (GNN) of a summation-type network is used in the present work for the estimation of the fundamental active and reactive components of the load current. The output calculations have been divided into two sections: forward calculations and reverse calculations.

With the help of Figure 3, the below mentioned equation is used to obtain the output of the summation part of the GNN:

$$
O_{\Sigma}=f_{1}\left(\Sigma W_{\Sigma i} X_{i}+X_{o \Sigma}\right)
$$

Similarly, the output of the product part of the GNN can be calculated as

$$
O_{\Pi}=f_{2}\left(\Pi W_{\Pi i} X_{i}+X_{o \Pi}\right)
$$

The output of the final GNN will be the sum of the summation part and product part which can be expressed as

$$
O_{i}=O_{\Sigma} * W_{\Sigma}+O_{\Pi}\left(1-W_{\Sigma}\right)
$$

In the above equation, $O_{\Sigma}$ denotes the output of the summation part of the neuron, $O_{\Pi}$ shows the output of the product part of the neuron, and $W$ depicts the weights. The proposed control strategy using GNN utilizes a GNN model to determine the fundamental active current components of the sensed load currents $\left(i_{L a}, i_{L b}, i_{L c}\right)$. The sensed load currents are the input to the proposed model which are further multiplied with weights $\left(w_{\Sigma p a}, w_{\Sigma p b}, w_{\Sigma p c}\right)$ and $\left(w_{\Pi p a}, w_{\Pi p b}, w_{\Pi p c}\right)$ at summation $\left(\Sigma_{A}\right)$ and product $(\Pi)$ neurons, respectively. At the initial level, these weights are referred as unknown weights and calculated by considering the in-phase unit templates $\left(u_{p a}, u_{p b}, u_{p c}\right)$ as the reference weights. A summation-type GNN structure for the calculation of fundamental active current component of a phase is given in Figure $3 \mathrm{~b}$.

The output calculations can be divided into two parts: forward calculations and reverse calculations. The aggregation function of $\Sigma_{A}$ and $\Pi$ of the forward mode calculations for phase " $a$ " is shown in Equations (8) and (9), respectively. Similarly, the aggregation function of $\Sigma_{A}$ and $\Pi$ of the forward mode calculations of another two phases, " $b$ " and " $c$ ", can be calculated.

$$
\begin{aligned}
\Sigma_{A_{P a}} & =i_{L a} w_{\Sigma p a}+i_{L b} w_{\Sigma p b}+i_{L c} w_{\Sigma p c}+\Sigma_{b i a s} \\
\Pi_{p a} & =i_{L a} w_{\Pi p a} * i_{L b} w_{\Pi p b} * i_{L c} w_{\Pi p c} * \Pi_{b i a s}
\end{aligned}
$$

$\Sigma_{\text {bias }}$ and $\Pi_{\text {bias }}$ represent the initial bias of the $\Sigma_{A}$ and $\Pi$ part of the structure, respectively. The proposed developed neuron has both $\Sigma$ and $\Pi$ aggregation functions. The $\Sigma_{A}$ aggregation function has been used with the sigmoidal characteristic function $f_{1}$, while the $\Pi$ aggregation function has been used with the Gaussian function $f_{2}$ as a characteristic 
function. The output of the $\Sigma_{A}$ part with a sigmoidal characteristic transfer function after threshold can be calculated as

$$
O_{\Sigma_{A p a}}=f_{1}\left(\Sigma_{A p a}\right)=\frac{1}{1+e^{-\lambda_{\Sigma p} * \Sigma_{A_{P a}}}}
$$

The output of the $\Pi$ part is threshold by using Gaussian transfer function and can be written as

$$
O_{\Pi p a}=f_{2}\left(\Pi_{p a}\right)=e^{-\lambda_{\Pi p} * \Pi_{p a}{ }^{2}}
$$

where $\lambda_{\Sigma p}$ and $\lambda_{\Pi p}$ are the gain scaling parameters of the $\Sigma_{A}$ and $\Pi$ part of the network, respectively, and are considered as unity here to avoid complexity. Similarly, output of the $\Sigma_{A}$ and $\Pi$ part of the forward mode calculations of other phases, " $b$ " and " $c$ ", are calculated as

$$
\begin{gathered}
O_{\Sigma_{A p b}}=f_{1}\left(\Sigma_{A p b}\right)=\frac{1}{1+e^{-\lambda_{\Sigma p} * \Sigma_{A_{P b}}}} \\
O_{\Pi p b}=f_{2}\left(\Pi_{p b}\right)=e^{-\lambda_{\Pi p} * \Pi_{p b}{ }^{2}} \\
O_{\Sigma_{A p c}}=f_{1}\left(\Sigma_{A p c}\right)=\frac{1}{1+e^{-\lambda_{\Sigma p} * \Sigma_{A_{P c}}}} \\
O_{\Pi p c}=f_{2}\left(\Pi_{p c}\right)=e^{-\lambda_{\Pi p} * \Pi_{p c}{ }^{2}}
\end{gathered}
$$

The final output of the GNN will be the function of two outputs and related to the weights $W$ and $(1-W)$, respectively, through the linear transfer function which can be written as

$$
\begin{aligned}
& O_{p a}=O_{\Pi p a}\left(1-W_{a}\right)+O_{\Sigma A p a} W_{a} \\
& O_{p b}=O_{\Pi p b}\left(1-W_{b}\right)+O_{\Sigma A p b} W_{b} \\
& O_{p c}=O_{\Pi p c}\left(1-W_{c}\right)+O_{\Sigma A p c} W_{c}
\end{aligned}
$$

where $W_{a}, W_{b}, W_{c}$ are weights associated with the phase " $a$ ", " $b$ " and " $c$ ", respectively. The mean active component of load currents $\left(w_{L p}\right)$ is obtained by averaging the final output of the GNN for each phase and is given as

$$
w_{L p}=\frac{\left(O_{p a}+O_{p b}+O_{p c}\right)}{3}
$$

However, the estimation of the fundamental reactive current component under the load current has been calculated by implementing the proposed GNN model. The sensed load currents $\left(i_{L a}, i_{L b}, i_{L c}\right)$ with their unknown weights, $\left(w_{A q a}, w_{A q b}, w_{A q c}\right)$ and $\left(w_{\Pi q a}, w_{\Pi q b}, w_{\Pi q c}\right)$, are processed as inputs to $\Sigma_{A}$ and $\Pi$ neurons. The aggregation function of $\Sigma_{A}$ and $\Pi$ of the forward mode calculations for phase " $a$ " is given in Equations (23) and (24), respectively. Similarly, the aggregation function of $\Sigma_{A}$ and $\Pi$ of the forward mode calculations of the other remaining phases " $b$ " and " $c$ " are calculated.

$$
\begin{gathered}
\Sigma_{A_{q a}}=i_{L a} w_{\Sigma q a}+i_{L b} w_{\Sigma q b}+i_{L c} w_{\Sigma q c}+\Sigma_{b i a s} \\
\Pi_{q a}=i_{L a} w_{\Pi q a} * i_{L b} w_{\Pi q b} * i_{L c} w_{\Pi q c} * \Pi_{b i a s}
\end{gathered}
$$

where $\Sigma_{\text {bias }}$ and $\Pi_{\text {bias }}$ denote the initial bias of the $\Sigma_{A}$ and $\Pi$ part of the network, respectively. Similarly, as explained above while calculating the fundamental active load current component, here also the $\Sigma_{A}$ aggregation function has been adopted along with the sigmoidal characteristic function $f_{1}$, whereas the $\Pi$ aggregation function has been adopted 
along with the Gaussian function $f_{2}$, taken as a characteristic function. The output of the $\Sigma_{A}$ part with a sigmoidal characteristic transfer function after threshold can be obtained as

$$
O_{\Sigma_{A q a}}=f_{1}\left(\Sigma_{A q a}\right)=\frac{1}{1+e^{-\lambda_{\Sigma q *} * \Sigma_{A q a}}}
$$

The output of the $\Pi$ part becomes threshold by using the Gaussian transfer function and can be written as given:

$$
O_{\Pi q a}=f_{2}\left(\Pi_{q a}\right)=e^{-\lambda_{\Pi q} * \Pi_{q a^{2}}}
$$

where $\lambda_{\Sigma q}$ and $\lambda_{\Pi q}$ are the gain scaling parameters of the $\Sigma_{A}$ and $\Pi$ part of the network, respectively, and are considered as unity here to avoid complexity. Similarly, the output of the $\Sigma_{A}$ and $\Pi$ part of the forward mode calculations of the other two phases " $b$ " and " $c$ " are calculated as

$$
\begin{gathered}
O_{\Sigma_{A q b}}=f_{1}\left(\Sigma_{A q b}\right)=\frac{1}{1+e^{-\lambda_{\Sigma q q} * \Sigma_{A q b}}} \\
O_{\Pi q b}=f_{2}\left(\Pi_{q b}\right)=e^{-\lambda_{\Pi q * \Pi_{q b}}{ }^{2}} \\
O_{\Sigma_{A q c}}=f_{1}\left(\Sigma_{A q c}\right)=\frac{1}{1+e^{-\lambda_{\Sigma q} * \Sigma_{A q c}}} \\
O_{\Pi q c}=f_{2}\left(\Pi_{q c}\right)=e^{-\lambda_{\Pi q} * \Pi_{q c}{ }^{2}}
\end{gathered}
$$

The output of the GNN model as a function of weights $W$ and $(1-W)$ can be written as

$$
\begin{aligned}
& O_{q a}=O_{\Pi q a}\left(1-W_{a 1}\right)+O_{\Sigma A p a} W_{a 1} \\
& O_{q b}=O_{\Pi q b}\left(1-W_{b 1}\right)+O_{\Sigma A q b} W_{b 1} \\
& O_{q c}=O_{\Pi q c}\left(1-W_{c 1}\right)+O_{\Sigma A q c} W_{c 1}
\end{aligned}
$$

where $W_{a 1}, W_{b 1}$ and $W_{c 1}$ are the weights associated with the $\Sigma_{A}$ and $\Pi$ part of the developed GNN model for the estimation of the fundamental reactive load current components. The fundamental reactive current component of the load current $\left(w_{L q}\right)$ is determined by taking the average of output of the GNN model for the reactive current component of the load currents and given as:

$$
w_{L q}=\frac{\left(O_{q a}+O_{q b}+O_{q c}\right)}{3}
$$

\subsubsection{GNN Weight Prediction and Updating Using Extended Kalman Filter (EKF)}

The Kalman Filter (KF) is a recursive algorithm used for estimating the state of a dynamic system in the case of less availability of data because of the presence of noise, etc. The KF algorithm utilizes the prior knowledge to predict the past, present and future state of the given system. The main advantage of the KF-based approach is less memory space requirements because the data are updated in each and every iteration. The basic KF theory is based on the probability of the hypothesis of the predicted state of the system under consideration by hypothesis of prior state and then using the available data from measurement sensors to correct the hypothesis to obtain the best estimation for each iteration. Two basic assumptions are made to derive the basic equations for KF to be optimal in the sense of mean square error, which should be described by a model of linear state space; the noises are white and Gaussian with zero mean, uncorrelated with each other.

$$
\begin{gathered}
x_{k+1}=F_{k+1, k} x_{k}+q_{k} \\
y_{k+1}=H_{k+1} x_{k+1}+r_{k+1}
\end{gathered}
$$


Equation (37) is known as a process equation. $x_{k}$ is a system state vector, a minimal set of data that uniquely defines the behavior of a system, and $k$ depicts discrete time. $F_{k+1, k}$ is the transition matrix to take the state $x_{k}$ from time $k$ to $k+1$, and $q_{k}$ is the additive process noise, white and Gaussian, with a zero mean and possessing a covariance matrix $Q_{k}$. The measurement step is shown in Equation (38), where $H_{k+1}$ is the measurement matrix, $y_{k+1}$ is observable at time $k+1$, and $r_{k+1}$ is the additive process noise, white and Gaussian, with a zero mean and possessing a covariance matrix $R_{k}$. Both noises are uncorrelated with each other. The KF algorithm works in two repeated functional steps:

The prediction step (time update): This step is to compute the estimation of state and error covariance.

$$
\begin{gathered}
\hat{x}^{-}{ }_{k+1}=F_{k+1, k} \hat{x}_{k} \\
P_{k+1}=F_{k+1, k} P_{k} F_{k+1, k}^{T}+Q_{k}
\end{gathered}
$$

where $P_{k}$ is there error covariance matrix.

Correction step (measurement update): This step is to correct the estimated state according to the previous step with the help of $y_{k+1}$

$$
\begin{gathered}
K_{k+1}=P^{-}{ }_{k+1} H^{T}{ }_{k+1}\left[H_{k+1} P^{-}{ }_{k+1} H^{T}{ }_{k+1}+R_{k+1}\right]^{-1} \\
\hat{x}_{k+1}=\hat{x}_{k}{ }^{-} K_{k+1}\left(y_{k+1}-H_{k+1} \hat{x}^{-}{ }_{k}\right) \\
P_{k+1}=\left(I-K_{k+1} H_{k+1}\right) P_{k+1}{ }^{-}
\end{gathered}
$$

where $K_{k+1}$ is the Kalman gain matrix.

The GNN model is a nonlinear system, so the basic KF approach should be extended by using the linearization process and is known as the extended Kalman Filter (EKF). The basic difference between KF and EKF is the linearization of the nonlinear system function performed by using the Jacobian matrix in EKF, and then rest of the KF steps can be applied. The nonlinear dynamic system can be defined by using the following equations:

$$
\begin{gathered}
x_{k+1}=x_{k}+q_{k} \\
y_{k+1}=h\left(x_{k+1}, u_{k+1}\right)+r_{k+1}
\end{gathered}
$$

Equation (44) depicts the state of a stationary process corrupted with process noise $q_{k}$, and state $x_{k}$ consists of network weights. $x_{k+1}$ is the weight vector matrix and input vector depicted by $u_{k+1}$. The noise covariance matrix can be written as $R_{k+1}=E\left[r_{k+1} r^{T}{ }_{k+1}\right]$ and $Q_{k+1}=E\left[q_{k+1} q^{T}{ }_{k+1}\right]$

In EKF, the linearization of measurement equation is carried out at each time step around the newest state estimation by using the first-order Taylor approximation. The GNN training problem is taken as a problem to find the state estimation of $x_{k+1}$ for minimizing the least square errors by implementing the previous calculations. $K_{k+1}$ Kalman gain can be written as

$$
\begin{gathered}
K_{k+1}=P_{k+1} H^{T}{ }_{k+1}\left[H_{k+1} P_{k+1} H^{T}{ }_{k+1}+R_{k+1}\right]^{-1} \\
\hat{x}_{k+1}=\hat{x}_{k+1}+K_{k+1}\left[y_{k+1}-h\left(\hat{x}_{k+1}+u_{k+1}\right)\right] \\
P_{k+1}=P_{k}-K_{k} H_{k} P_{k}+Q_{k}
\end{gathered}
$$

\subsubsection{Reference Current Calculation}

The fundamental real power current component of the load current can be obtained as

$$
I_{L p}=w_{p d}+w_{L p}-w_{P V}
$$

The reference active components of the grid currents can be written as

$$
i_{p s a}=I_{L p} * u_{p a}, i_{p s b}=I_{L p} * u_{p b}, i_{p s c}=I_{L p} * u_{p c}
$$


Similarly, the fundamental reactive current component of a load current can also be obtained as

$$
I_{L q}=w_{q t}+w_{L q}
$$

The grid currents' active reference components can be written as

$$
i_{q s a}=I_{L q} * u_{q a}, i_{q s b}=I_{L q} * u_{q b}, i_{q s c}=I_{L q} * u_{q c}
$$

The net fundamental reference grid currents $\left(i_{s a}^{*}, i_{s b}^{*}, i_{s c}^{*}\right)$ can be obtained as

$$
i_{s a}^{*}=i_{p s a}+i_{q s a}, i_{s b}^{*}=i_{p s b}+i_{q s b}, i_{s c}^{*}=i_{p s c}+i_{q s c}
$$

VSC gating signals have been generated by comparing reference $\left(i_{s a}^{*}, i_{s b}^{*}, i_{s c}^{*}\right)$ and actual $\left(i_{s a}, i_{s b}, i_{s c}\right)$ grid currents for an individual phase, and the error is processed through the PI current regulator. A hysteresis current regulator is used for indirect current control.

\section{Results}

The SPV array is designed for a maximum power rating of $10 \mathrm{~kW}$. The given system is designed, developed and simulated using the MATLAB/Simulink platform. The performance evaluation of the proposed system is carried out under a linear and nonlinear load with dynamic changes and a changing solar irradiance scenario.

\subsection{Performance Analysis of Proposed Controller for Linear Load for PFC}

The performance of the proposed EKF-based GNN controller is evaluated with a combined structure of the summation and product neurons collectively in single layer. In the proposed GNN network, each processed neuron consists of different weights with the inputs as measured load currents $\left(i_{L a}, i_{L b}, i_{L c}\right)$. With the help of this, the summation weights $\left(w_{\Sigma p a}, w_{\Sigma p b}, w_{\Sigma p c}\right)$ and product weights $\left(w_{\Pi p a}, w_{\Pi p b}, w_{\Pi p c}\right)$ are estimated. The proposed GNN is trained to calculate the unspecified weights and EKF filter which is used to predict and update the weights of the GNN network. The output of the proposed system is evaluated under the influence of several performance parameters, i.e., grid voltage $\left(v_{S}\right)$, grid current $\left(i_{S}\right)$, load current $\left(i_{L}\right)$, voltage source converter current $\left(i_{\text {vsc }}\right)$, grid real power $\left(P_{g}\right)$, grid re-active power $\left(Q_{g}\right)$, PCC terminal voltage $\left(V_{t}\right)$, SPV power $\left(P_{p v}\right)$, SPV array current $\left(I_{p v}\right)$ and voltage at direct current link $\left(V_{d c}\right)$, provided in Figure $4 \mathrm{a}, \mathrm{b}$ in steady-state linear load (at $t=0.2$ to $0.3 \mathrm{~s}$ ) conditions. Intermediate signals are given in Figure $4 \mathrm{~b}$, which depicts the performance parameters and corresponding weights with a variation in error between the active fundamental components of the load currents. The SPV system remains in operation for feeding the maximum value of power onto the load and grid at unity power factor (UPF). 

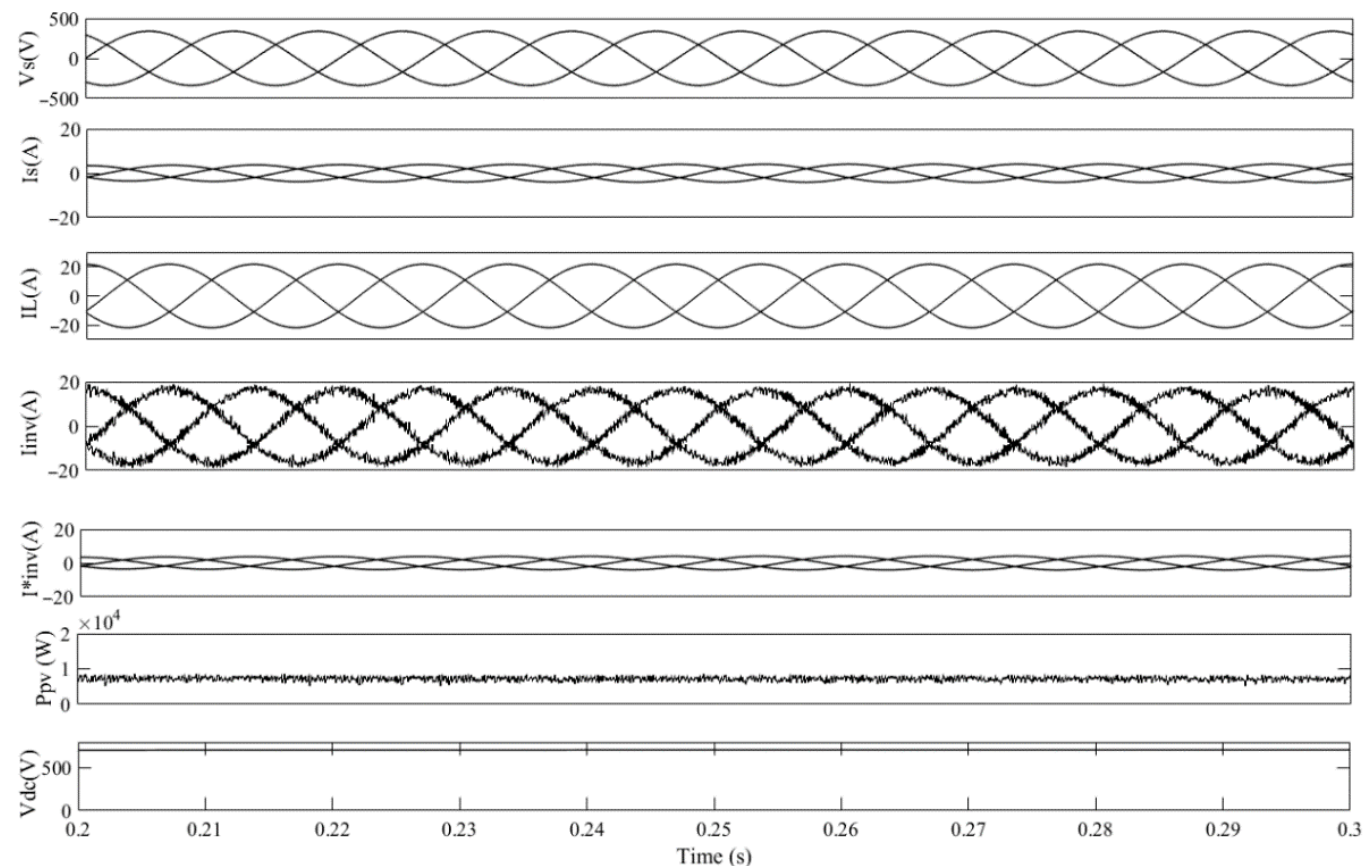

(a)

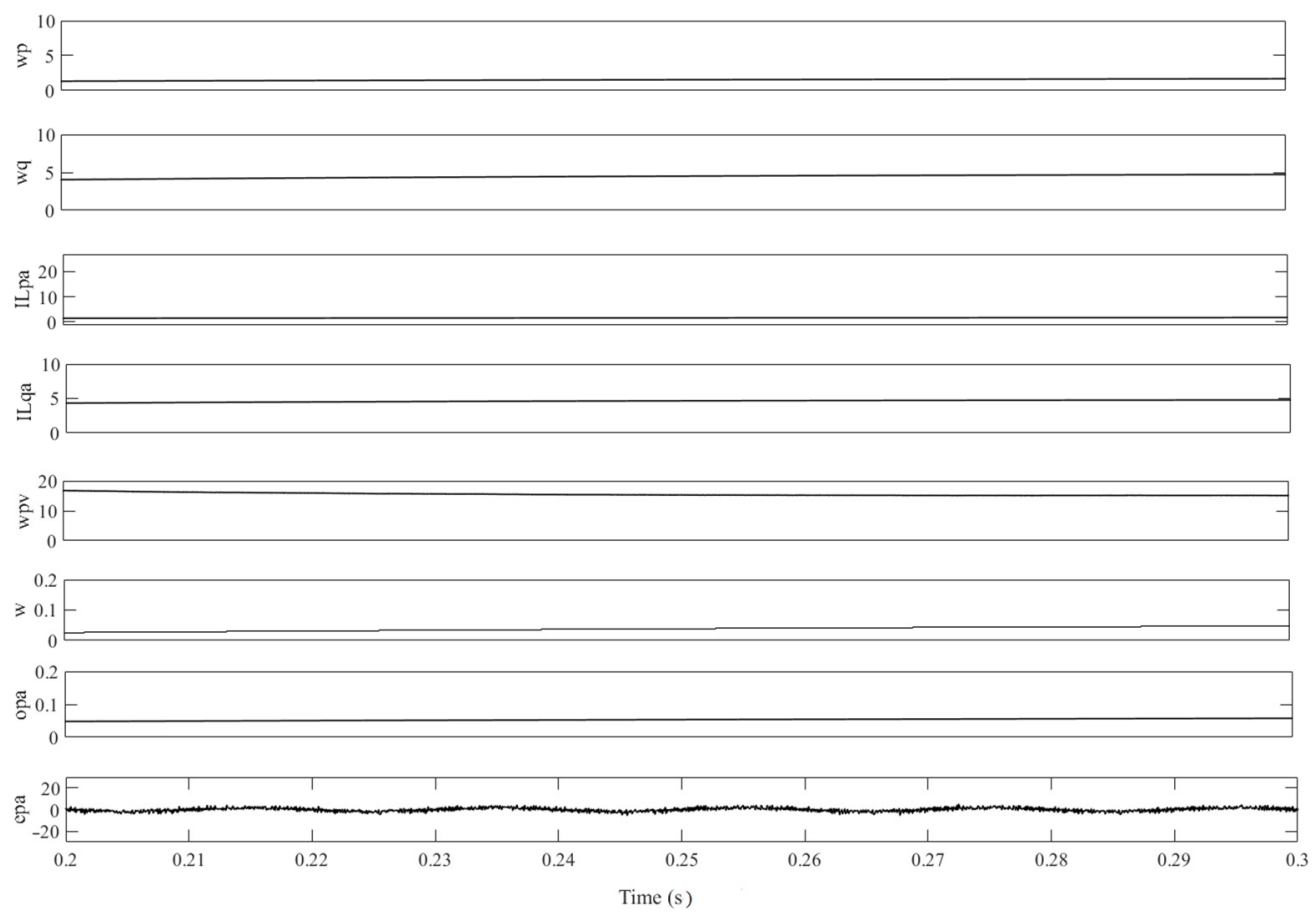

(b)

Figure 4. (a) Performance parameters, (b) estimated weights under steady-state linear load conditions in PFC mode.

4.2. Performance Analysis of Proposed Controller Considering Dynamic Linear Load for Zero Voltage Regulation (ZVR)

If the load is drawing reactive power with unbalanced behavior, then a change in the terminal voltage $\left(V_{t}\right)$ occurs at the point of common coupling. Figure $5 \mathrm{a}, \mathrm{b}$ shows the behavior of the given system for dynamic linear loading conditions under a zero voltage regulation (ZVR) mode. It can be observed from the results after phase " $c$ " of the load is taken out from the supply at $1.1 \mathrm{~s}$, the grid currents $\left(i_{s}\right)$ remain sinusoidal with the help of a voltage source converter. The PCC voltage $\left(V_{t}\right)$ and voltage at the DC junction are 
maintained at set values, which are $415 \mathrm{~V}$ and $700 \mathrm{~V}$, respectively, without any fluctuations. Intermediate signals are provided in Figure 5b, which shows the performance parameters and corresponding weights with a variation in error between the active fundamental components of the load currents. The reactive power $(\mathrm{Qg})$ taken from the utility grid is approximately equivalent to 0 , for compensating the linear loads using reactive power.
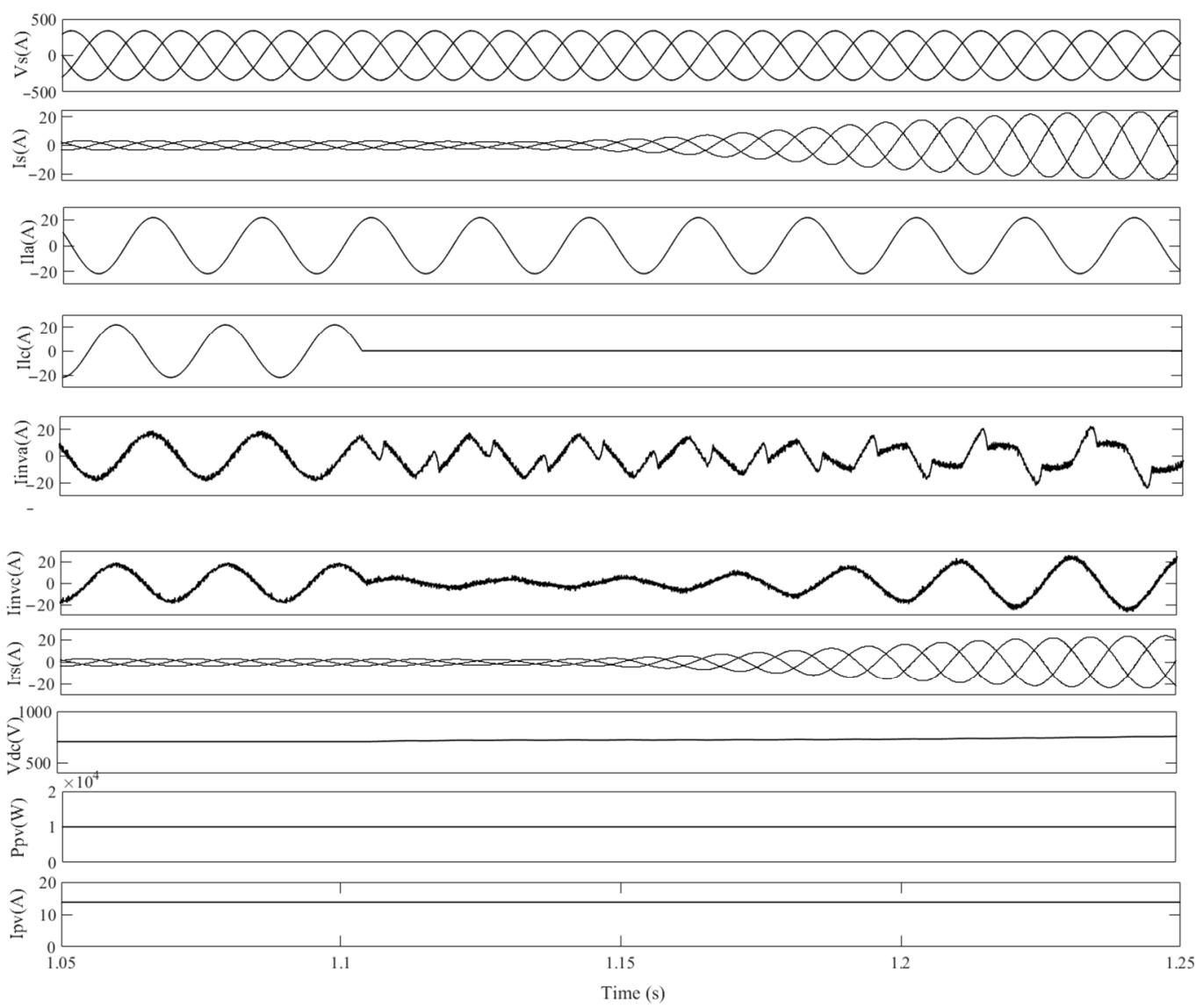

(a)

Figure 5. Cont. 

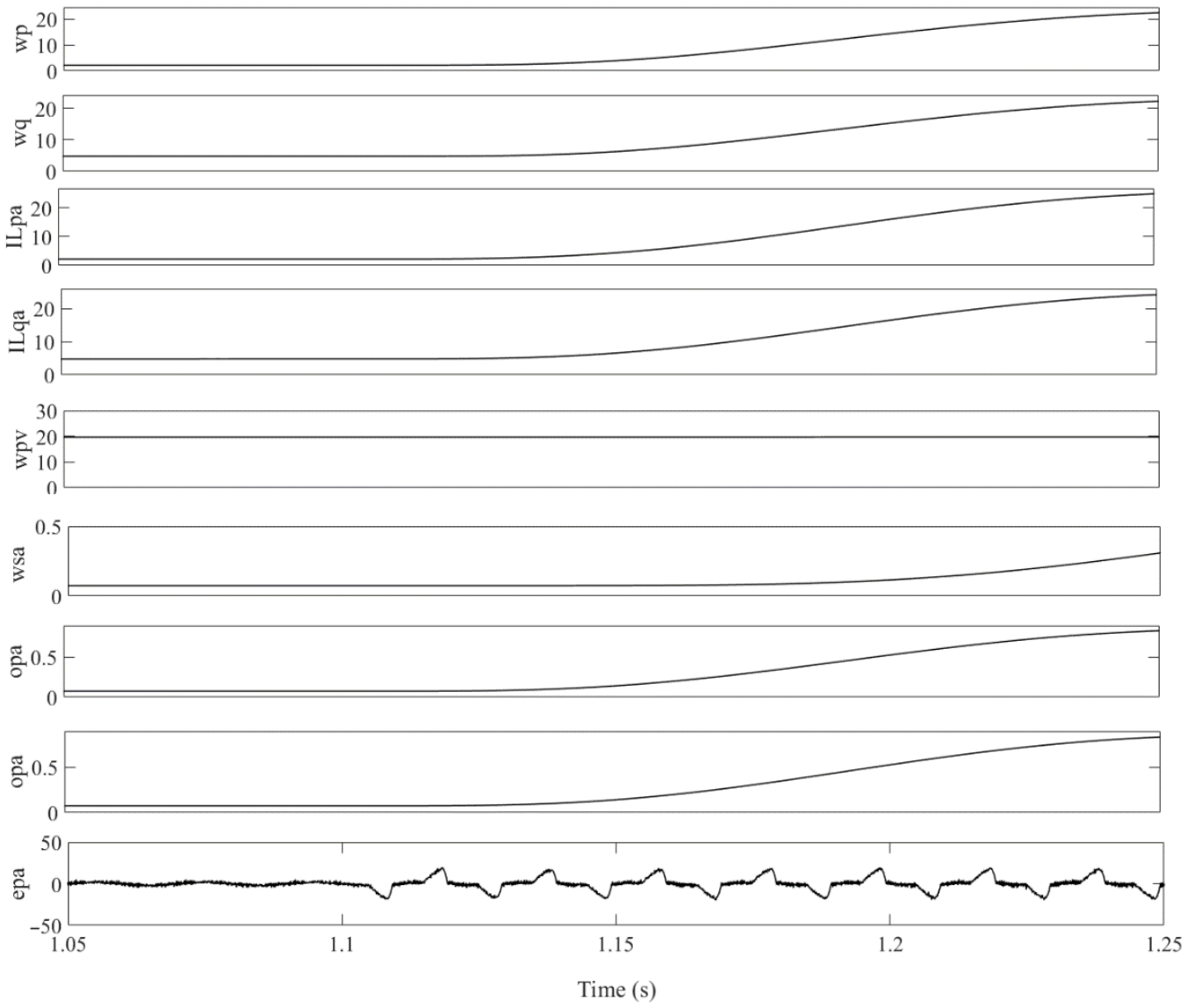

(b)

Figure 5. (a) Performance parameters, (b) estimated weights under dynamic linear load conditions for zero voltage regulation (ZVR).

\subsection{Performance under a Nonlinear Load}

Figure $6 \mathrm{a}, \mathrm{b}$ show the behavior of a developed system for dynamic nonlinear loads under the zero voltage regulation (ZVR) mode. By using the given control algorithm, the grid current $\left(i_{s}\right)$ is sinusoidal in nature, when the load of phase " $c$ " is extracted at $1.1 \mathrm{~s}$. Intermediate signals are given in Figure $6 \mathrm{~b}$ for corresponding weight signals with a variation in error between the active fundamental components of the load currents. $W_{p a}$ of the linear transfer function $\Sigma$ and the estimated GNN output of the active current component of the load current are represented by $O_{p a}$, and its actual value is achieved by scaling and depicted by $I_{L p a}$. This indicates that the calculated weights change according to the load condition. Figure 7a,c show the total harmonic distortion (THD) at the point of common coupling for phase " $a$ " of a load current, grid current and grid voltage, respectively, and obtained as $37.48 \%, 1.04 \%$ and $1.07 \%$, respectively, which is within acceptable limits of harmonics in utility currents and voltage fluctuations according to the IEEE-519 and IEEE-1547 standards. THD analysis of the given system is provided in Table 1 for a nonlinear load. 

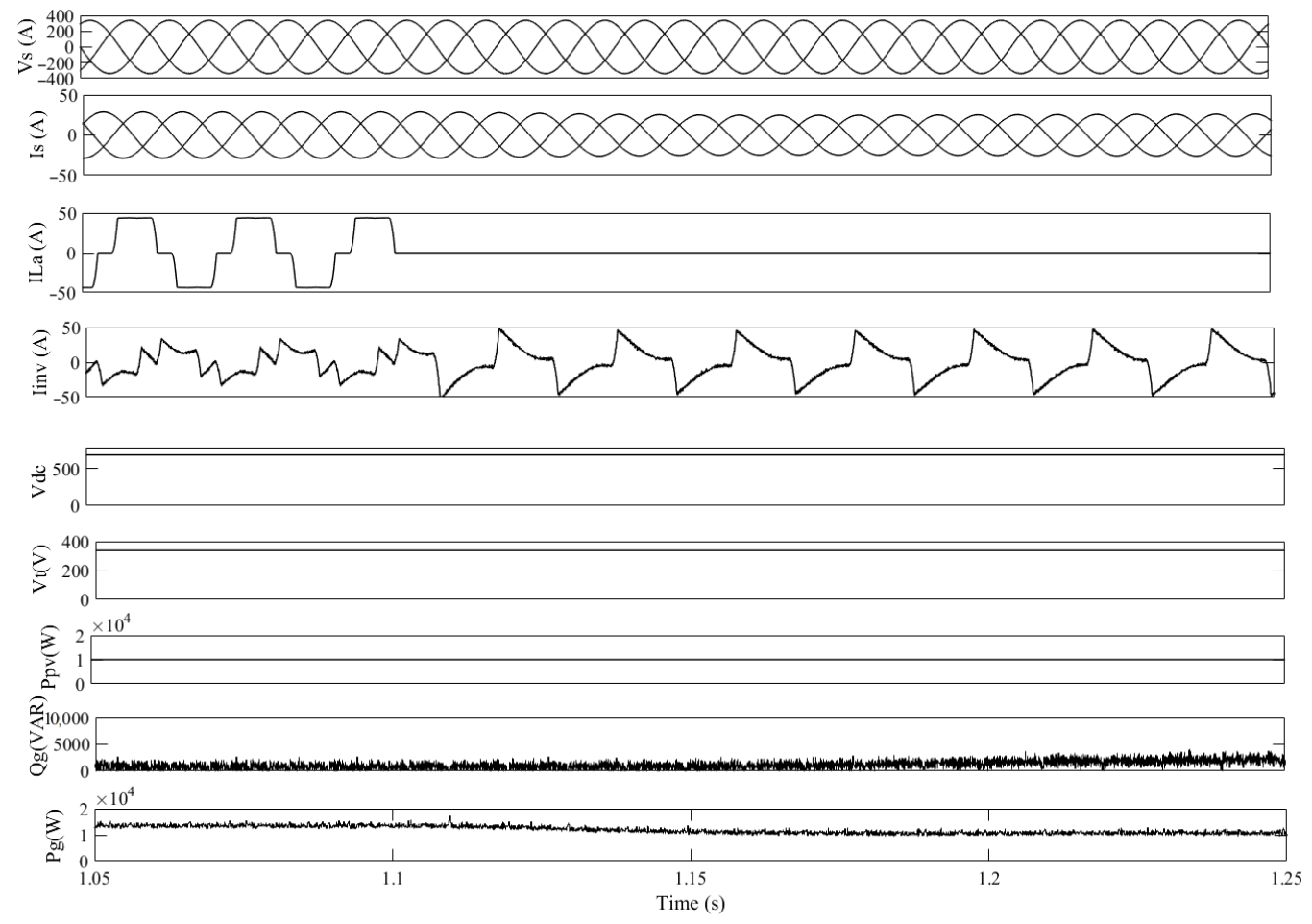

(a)
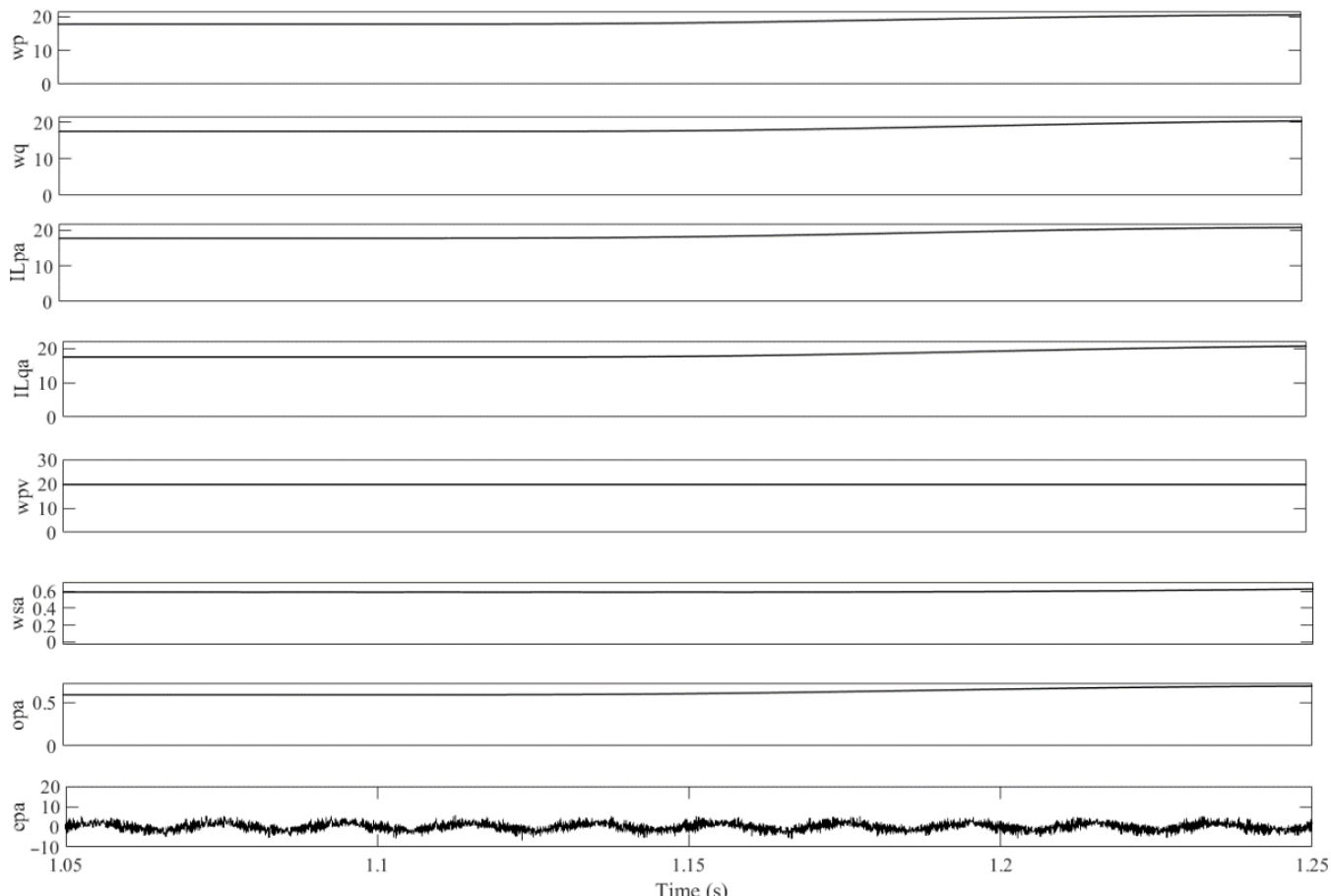

(b)

Figure 6. (a) Performance indices, (b) weights with training parameters for phase " $a$ " with steady-state loading in PFC mode. 

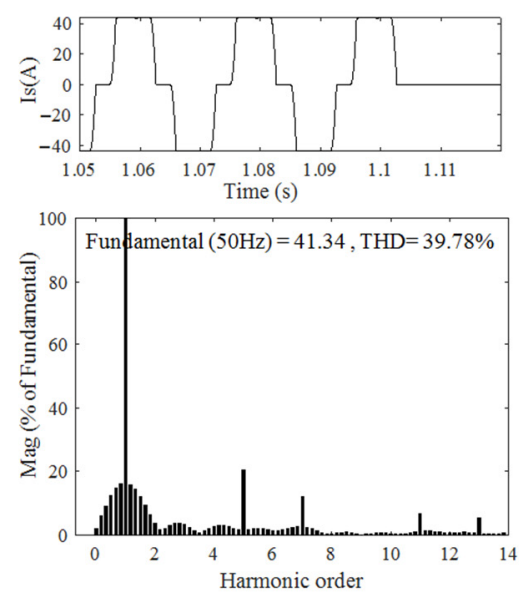

(a)
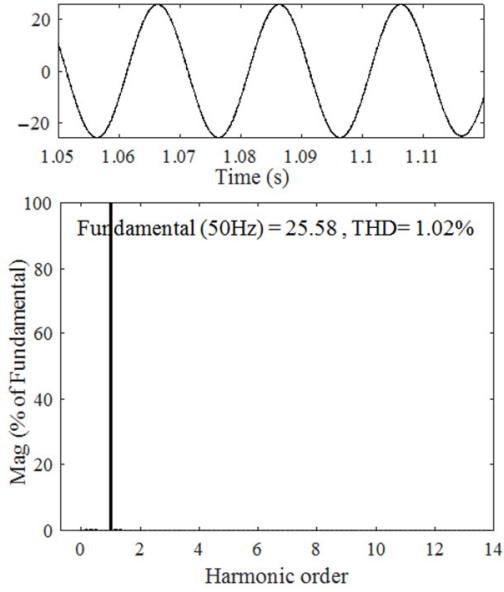

(b)
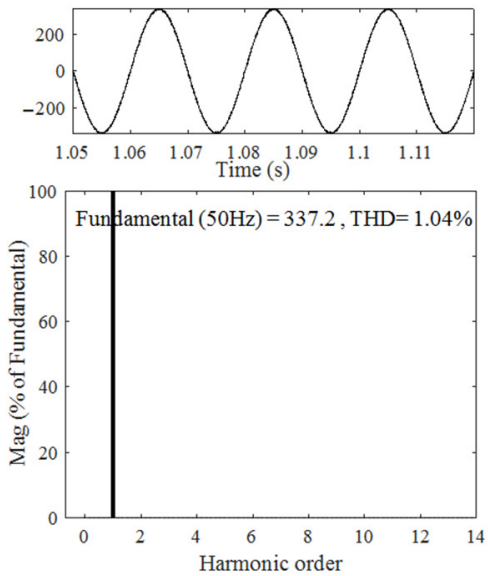

(c)

Figure 7. Total harmonic distortion (THD) for (a) load current of phase " $a$ ", (b) grid current and (c) grid voltage in ZVR mode.

Table 1. Parameters of the developed system for the proposed controller.

\begin{tabular}{cccc}
\hline Operating Mode & Parameters & $\begin{array}{c}\text { GNN Based Control } \\
\text { Algorithm }\end{array}$ & $\begin{array}{c}\text { EKF GNN Based } \\
\text { Control Algorithm }\end{array}$ \\
\hline ZVR & $\begin{array}{c}\text { Grid voltage (V), } \\
\text { \%THD at PCC } \\
\text { Grid current (A), } \\
\text { \%THD at PCC } \\
\text { Load current (A), } \\
\text { \%THD at PCC }\end{array}$ & 2333.02 V, 1.89\% & $337.2 \mathrm{~V}, 1.04 \%$ \\
\hline
\end{tabular}

\subsection{Performance Analysis at Varying Solar Irradiance}

Dynamic behavior of the developed system is also observed under varying solar irradiance conditions. The solar irradiance (S) is raised to $1000 \mathrm{~W} / \mathrm{m}^{2}$ from $600 \mathrm{~W} / \mathrm{m}^{2}$ at $0.5 \mathrm{~s}$. The SPV feeds the connected load and excess amount of power output provided to the utility grid. As shown in the results, the grid power $\left(P_{g}\right)$ decreases after $0.5 \mathrm{~s}$ because of an increase in power $\left(P_{p v}\right)$ output from SPV, given in Figure 8 . The proposed system under variable solar irradiance remains operating at the maximum power point of the SPV array and works at unity power factor. The grid side current is maintained to be sinusoidal, and the voltage at DC link is also maintained at a set point.

\subsection{Comparative Study of Developed Algorithm with Other Conventional Approaches}

The proposed algorithm is analyzed for different scenarios and found accurate as per the desired performance. The parameters of proposed EKF GNN-based controller is presented in Table 1 and compared with the GNN approach. The developed EKF GNN based control approach is found better than ANN conventional approaches such as ADALINE and multilayer perceptron neural network (MLPN). A comparative analysis is made and presented in Table 2 under dynamic nonlinear load conditions on the basis of various performance parameters. The smaller number of unknown weights required and a single layer enhanced the performance of the controller. Additionally, the weight update time, settling period and maximum change in DC voltage is less for the proposed technique. 

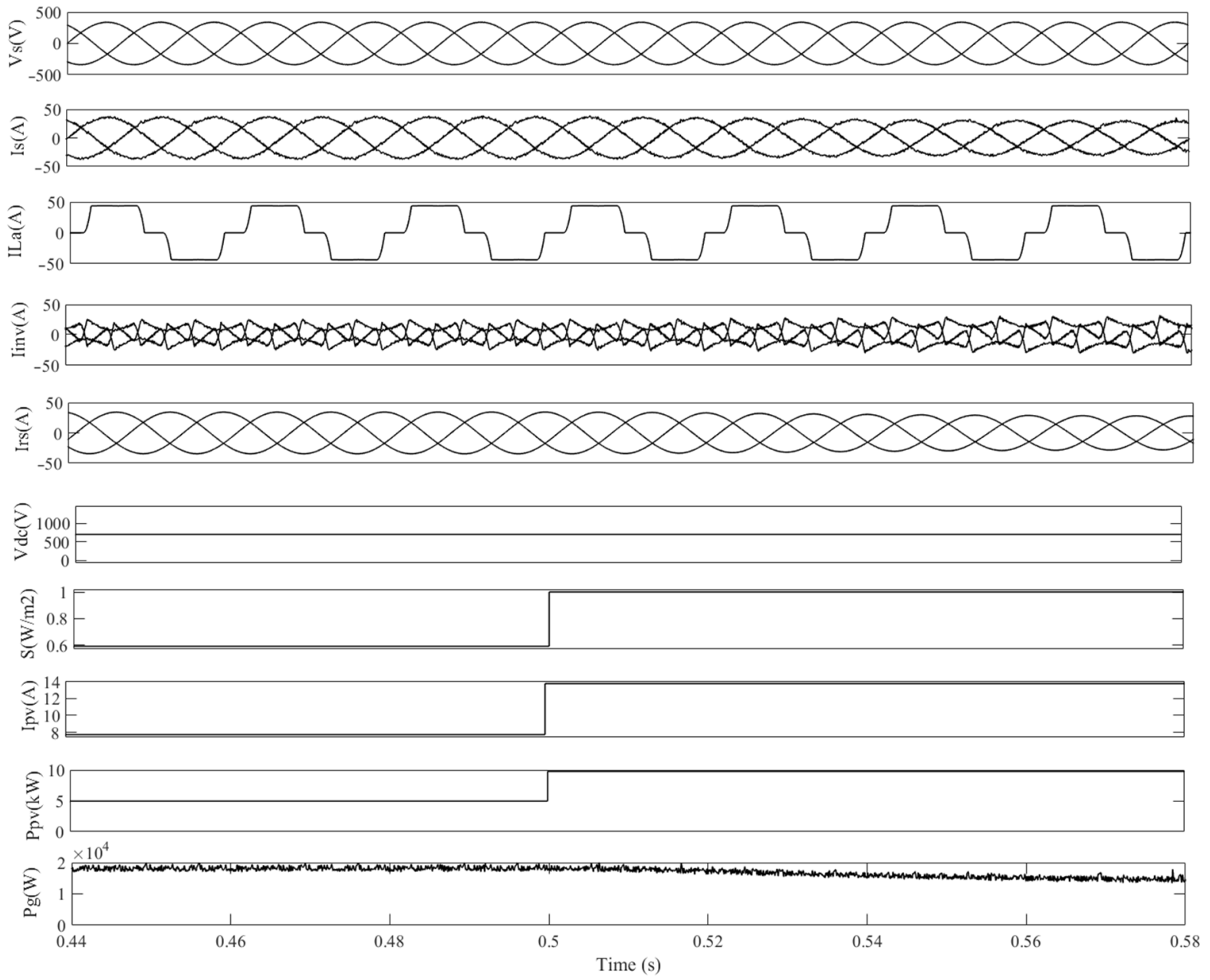

Figure 8. Analysis of performance for a non-linear load with variable solar irradiance.

Table 2. Comparative performance analysis of the proposed technique.

\begin{tabular}{cccc}
\hline $\begin{array}{c}\text { Performance } \\
\text { Parameters }\end{array}$ & ADALINE & MLPN & GNN \\
\hline Training & Least Mean Square & Back Propagation & EKF \\
Learning & Gradient decent (GD) & GD/GDM & GDM \\
Layers & Two & Three & One \\
Training pattern & Online Training & $\begin{array}{c}\text { Offline stochastic } \\
\text { training }\end{array}$ & Online training \\
Estimation nature & Linear & Nonlinear & Both types \\
Transfer function & Linear & Sigmoidal & All \\
Weight update Time & $15.7 \mu \mathrm{s}$ & $82 \mu \mathrm{s}$ & $6 \mu \mathrm{s}$ \\
$\begin{array}{c}\text { Settling period of DC } \\
\text { link }\end{array}$ & 1 cycle & $2 \frac{1}{2}$ cycle & 1 cycle \\
Max change in DC & $4.5 \mathrm{~V}$ & $10 \mathrm{~V}$ & $3.7 \mathrm{~V}$ \\
link voltage & & & \\
\hline
\end{tabular}

Figure 9 shows the performances by experimenting the given system in power factor correction mode by implementing linear and nonlinear loads. It depicts the voltage source current $\left(I_{v s c}\right)$, load current $\left(I_{L a}\right)$, grid current $\left(I_{g}\right)$ and direct current link voltage $\left(V_{d c}\right)$. Phase " $a$ " gid voltage and grid current are shown in Figure 10; it also shows the performances of the controller under PFC mode. 


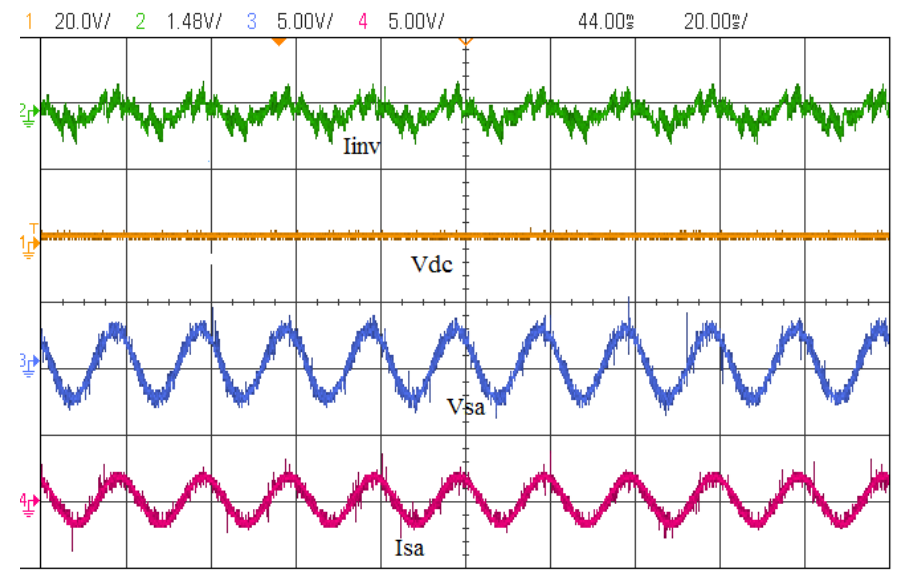

Figure 9. Performance parameters under linear load for the extended Kalman filter (EKF) GNN.

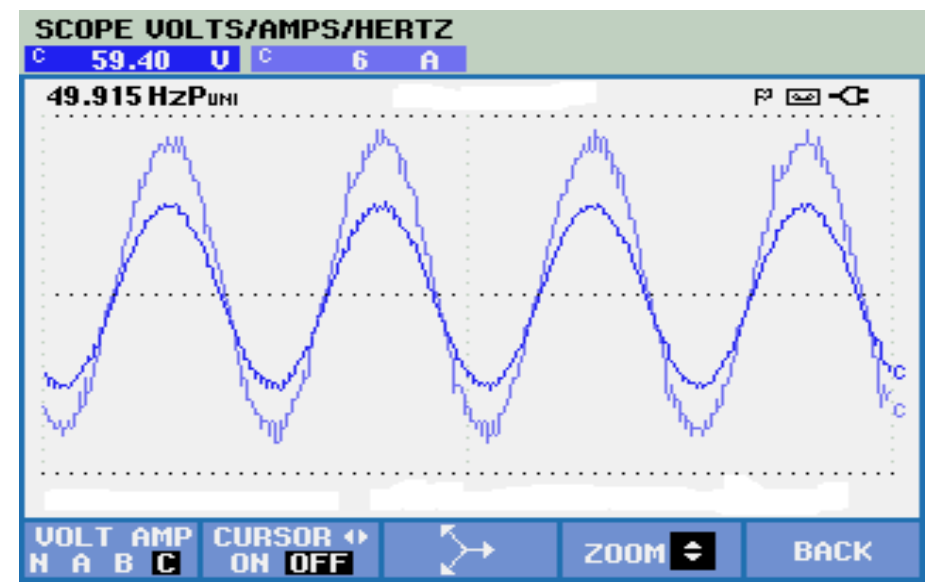

Figure 10. Source side voltage and current of phase " $a$ " under the power factor correction mode.

Figure 11 provides the performance of the SPV plant for nonlinear loads, whereas Figure 12a depicts non-linear current and Figure 12b depicts the source current and voltages for phase " $a$ ". The THD of the load current is given in Figure 13.

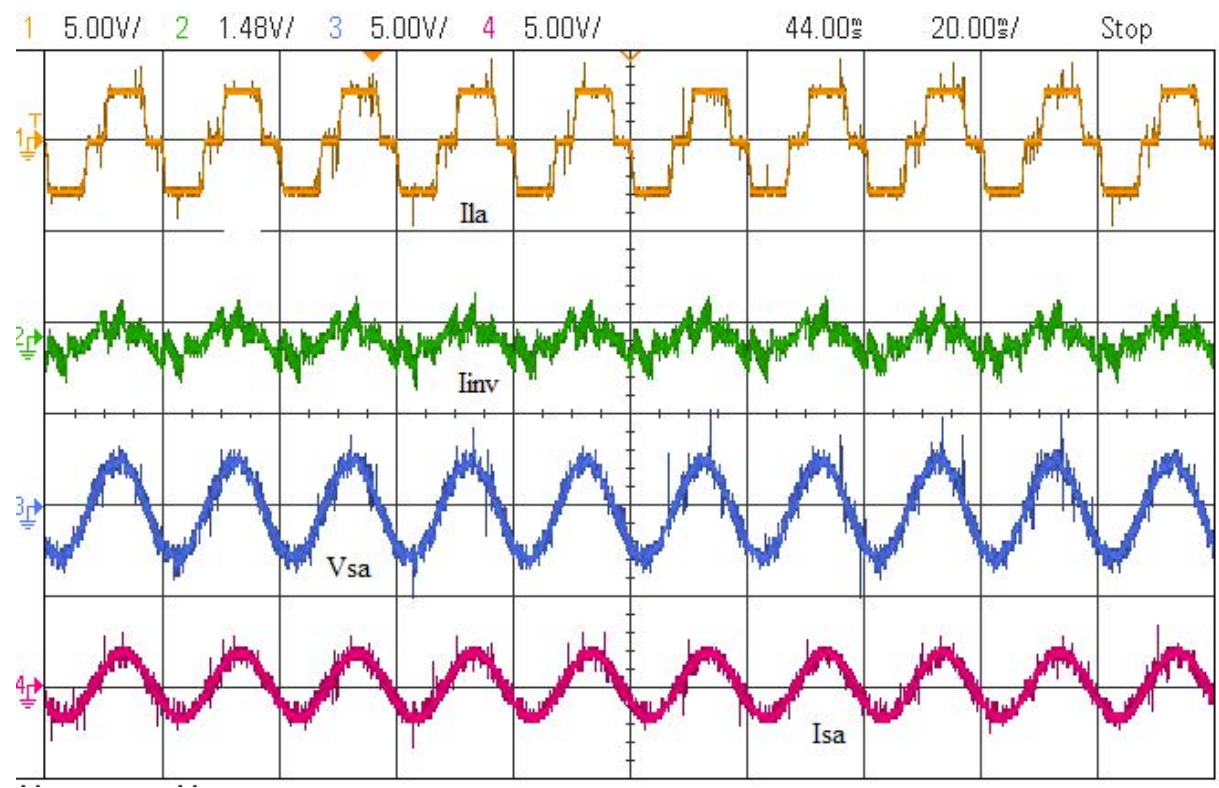

Figure 11. Performance analysis considering non-linear load conditions for EKF GNN. 


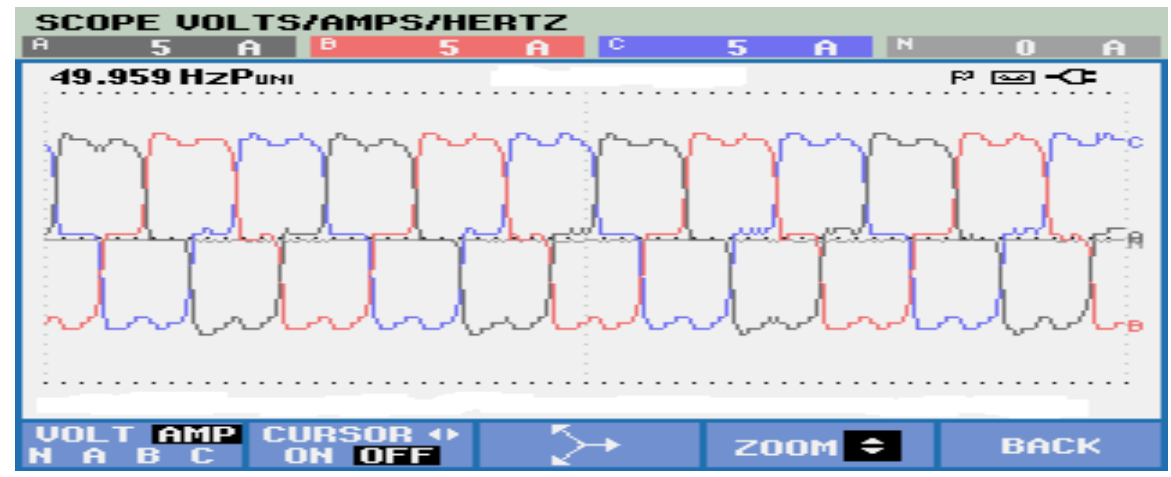

(a)

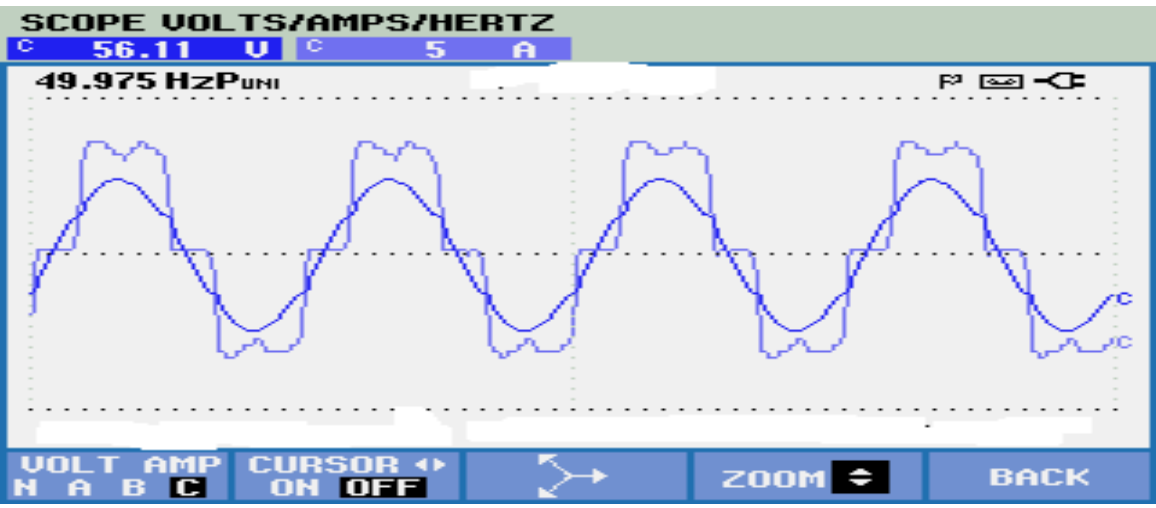

(b)

Figure 12. (a) Non-linear current, (b) current and voltage of phase " $a$ ".

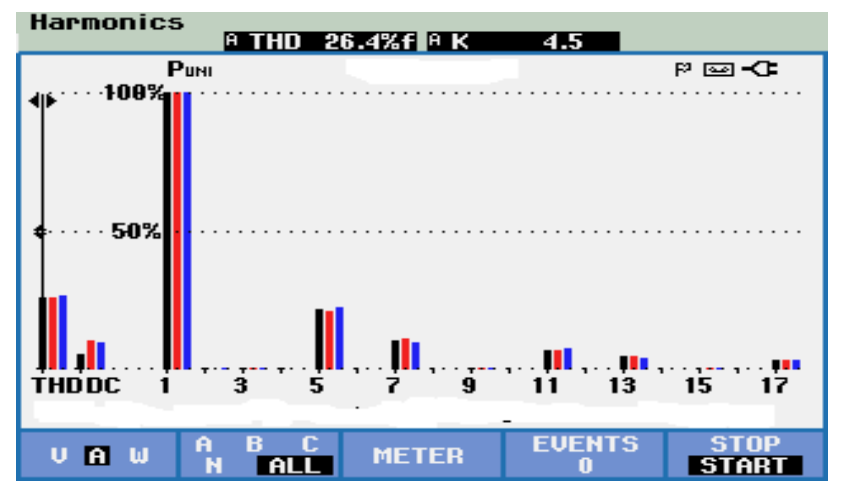

(a)

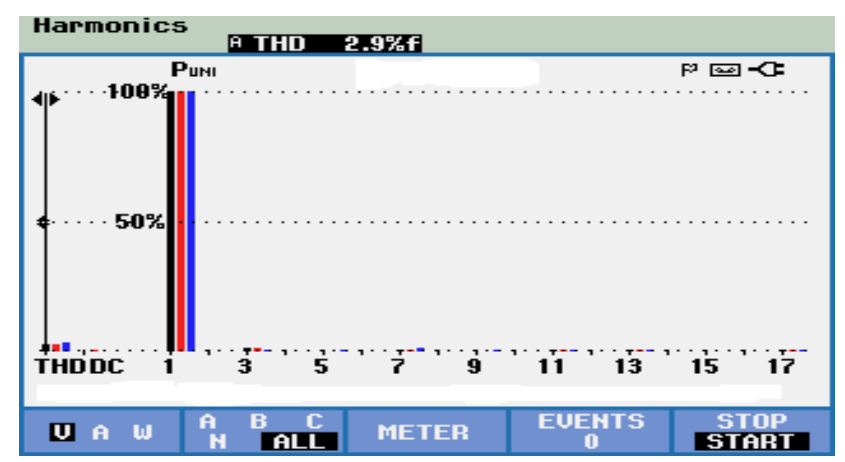

(b)

Figure 13. (a) THD spectrum of nonlinear load, (b) improved THD for grid current under nonlinear load. 
The performance of the proposed controller under nonlinear dynamic load is shown in Figure 14; when load of phase " $b$ " is removed, the grid current is reduced. Further, the performance of intermediate signals for different weights is also shown in Figure 15. Figures 16 and 17 show the controller performance under variable solar irradiance.

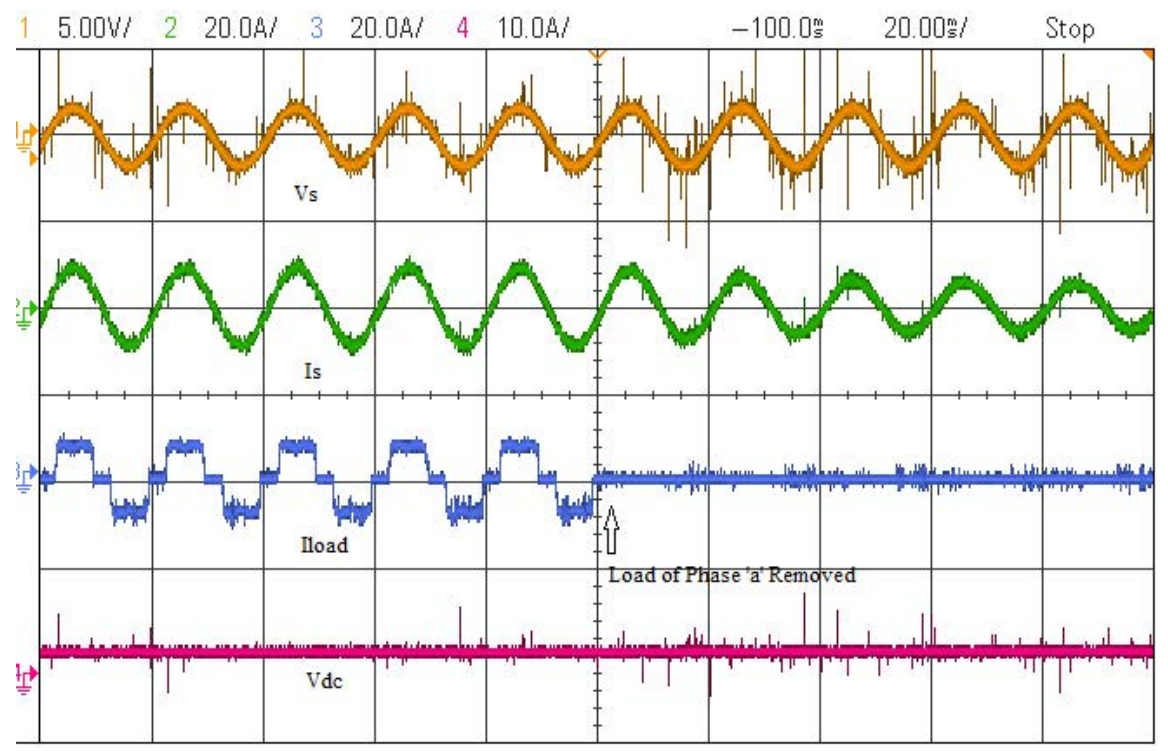

Figure 14. Performance parameters under dynamic nonlinear load for EKF GNN.

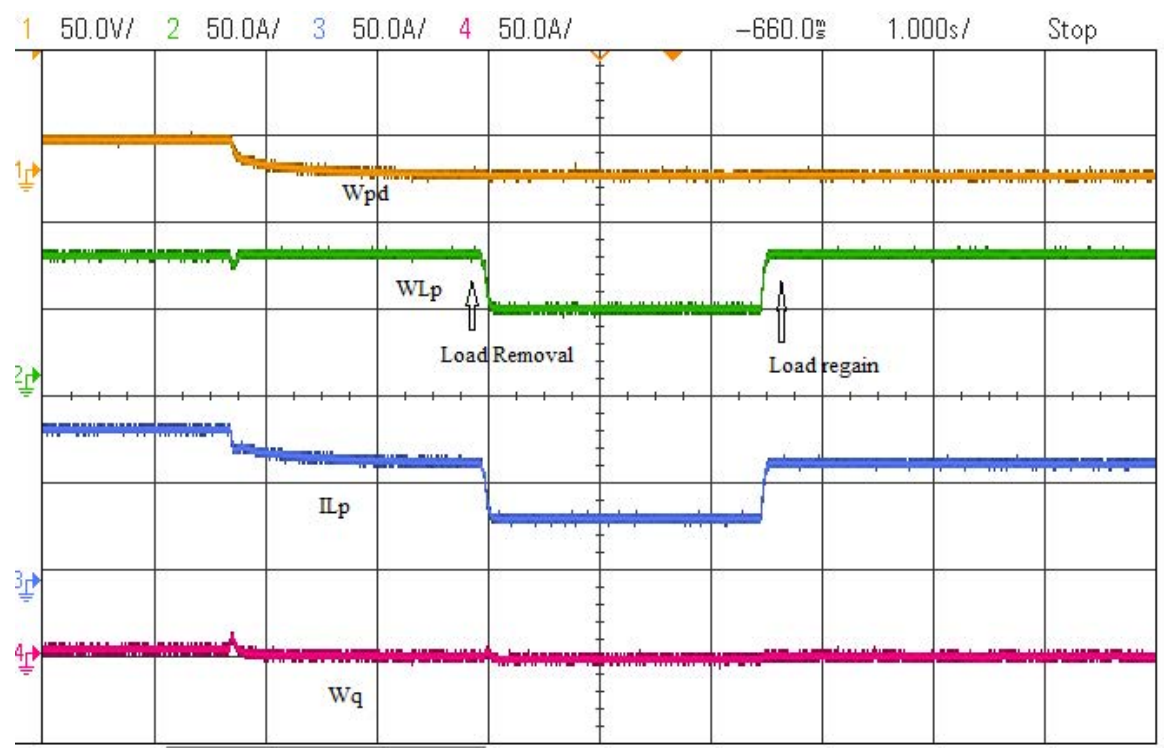

Figure 15. Performance of intermediate weight signals under dynamic nonlinear load for EKF GNN. 


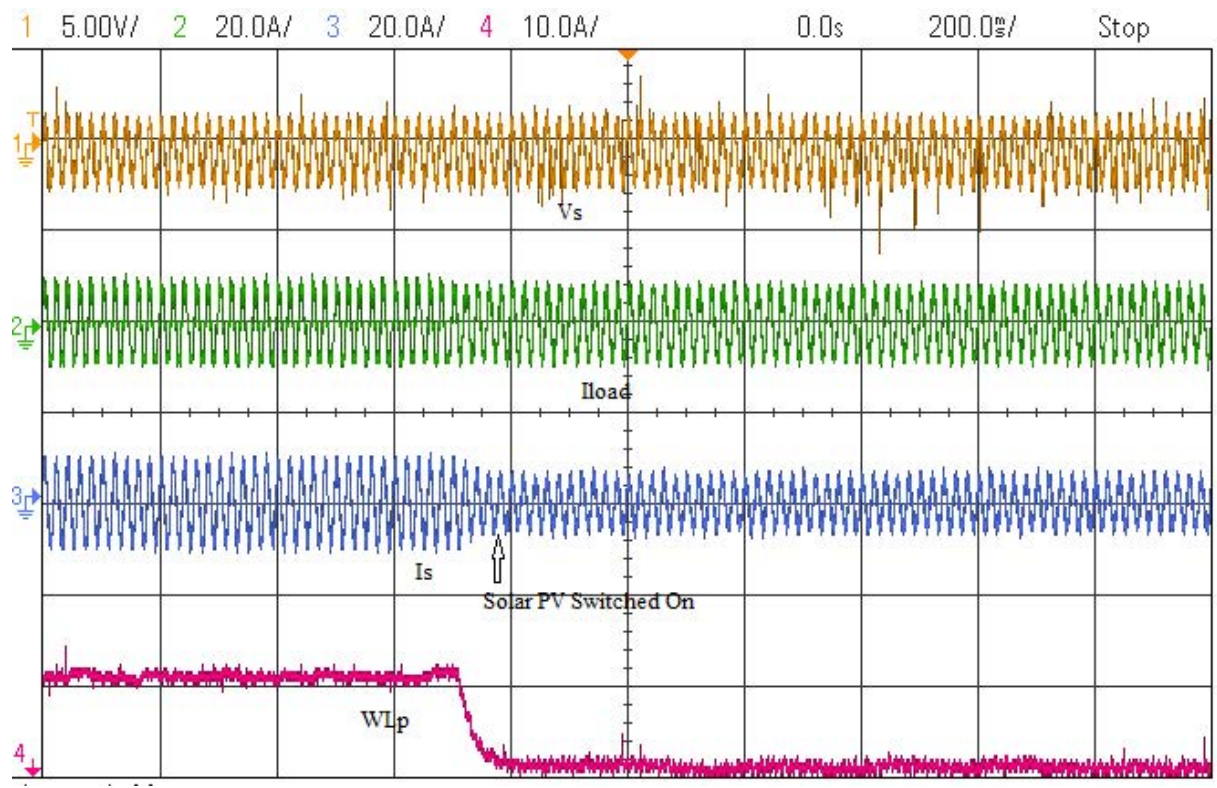

Figure 16. Performance parameters under nonlinear load with solar PV ON for EKF GNN.

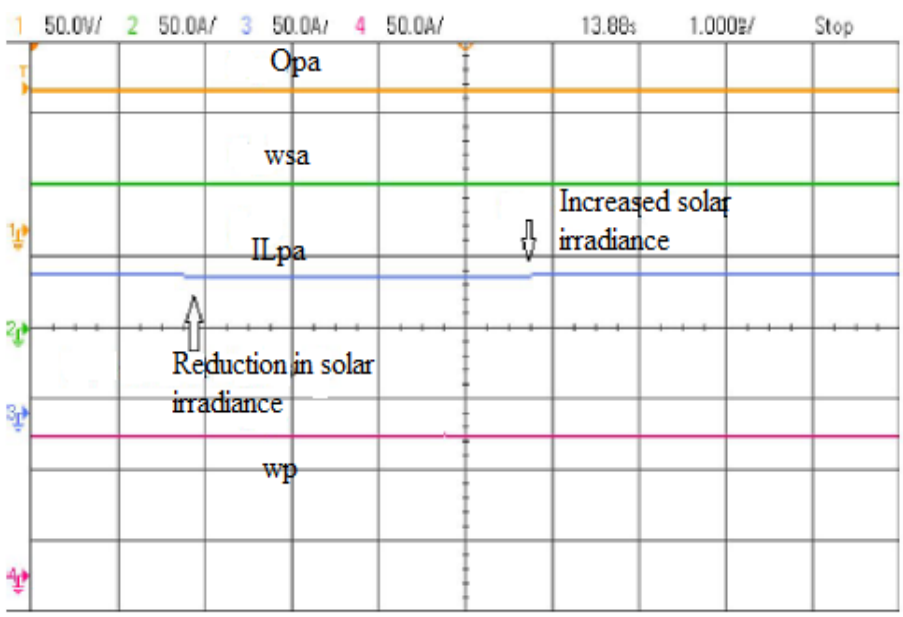

Figure 17. Performance parameters under variable solar irradiance for EKF GNN.

\section{Conclusions}

The proposed system was developed and tested using MATLAB simulation environment, and the performance of the EKF GNN-based VSC control approach was validated under linear and nonlinear loads for static and dynamic scenarios. The proposed EKF GNN approach has successfully improved the function of the developed SPV system. The performance of the developed system was found satisfactory under load unbalancing and varying solar irradiance. Additionally, it continues to operate in a UPF mode of operation, providing reactive power compensation, load balancing, MPP extraction and harmonics compensation. A changeable step size perturb and observe (P\&O) MPPT approach was utilized in this research and enabled fast tracking of MPP and convergence. Moreover, single-stage topology was able to reduce the losses in semiconductor devices and increase the overall efficiency.

The proposed control approach performs with more flexibly in training the network under dynamic conditions and provides improved online learning. This control technique needs a smaller number of training patterns and unknown weights and hence reduces the complexity and the computational time. The developed system obtains acceptable limits of harmonics in utility currents and voltage fluctuations according to the IEEE-519 and IEEE-1547 standards. 
Author Contributions: Conceptualization, P.C., M.R. and I.A.; methodology, P.C., M.A. and M.R.; validation, P.C. and I.A.; formal analysis, P.C., I.A., M.A. and M.R.; resources, M.R. and I.A.; writingoriginal draft, P.C. and M.R.; writing-review and editing, P.C., I.A., M.R. and M.A.; visualization, P.C.; supervision, M.R.; funding acquisition, I.A., M.A. and M.R. All authors have read and agreed to the published version of the manuscript.

Institutional Review Board Statement: Not applicable.

Informed Consent Statement: Not applicable.

Data Availability Statement: No data are used here.

Acknowledgments: Researchers would like to thank the Deanship of Scientific Research, Qassim University for funding publication of this project.

Conflicts of Interest: The authors declare no conflict of interest.

\section{Nomenclature}

\begin{tabular}{|c|c|}
\hline C & DC link capacitor $(\mu \mathrm{F})$ \\
\hline$f_{1}$ & Sigmoidal characteristic function \\
\hline$f_{2}$ & Gaussian characteristic function \\
\hline$I_{\text {inv }}$ & Inverter output current \\
\hline$I^{*}$ inv & Reference Inverter output current \\
\hline$i_{L a}, i_{L b}, i_{L c}$ & Load currents of phase ' $a$ ', ' $b$ ' and ' $c$ ' respectively (Ampere) \\
\hline$I_{L p}$ & Fundamental active current component \\
\hline$I_{\text {Lpa }}$ & Fundamental active current component for phase ' $a$ ' \\
\hline$I_{L q}$ & Fundamental reactive current component \\
\hline$I_{\text {Lqa }}$ & Fundamental reactive current component for phase ' $a$ ' \\
\hline$I_{M P P}$ & PV current at maximum power point (Ampere) \\
\hline$i_{p s a}$ & Active reference component of grid current \\
\hline$I_{P V}$ & PV array output current (Ampere) \\
\hline$i_{q s a}$ & Reactive reference component of grid current \\
\hline$I_{r s}$ & Reference component of grid current \\
\hline$i_{s a}, i_{s b}, i_{s c}$ & Grid currents of phase ' $a$ ', ' $b$ ' and ' $c$ ' respectively (Ampere) \\
\hline$i_{s a}^{*}, i_{s b}^{*}, i_{s c}^{*}$ & Reference currents of phase ' $a$ ', ' $b$ ' and ' $c$ ' respectively (Ampere) \\
\hline$K_{i}$ & Integral gain of PI controller \\
\hline$K_{p}$ & Proportional gain of PI controller \\
\hline$L_{f}$ & Interfacing inductor $(\mathrm{mH})$ \\
\hline$O_{i}$ & Final output of generalized neuron \\
\hline$O_{p a}$ & output of the GNN model for active component \\
\hline$O_{q a}$ & output of the GNN model for reactive component \\
\hline $\mathrm{O}_{\Sigma}$ & Output of $\Sigma_{A}$ part network \\
\hline$O_{\Pi}$ & Output of $\Pi$ part network \\
\hline$P_{p v}$ & PV power $(W)$ \\
\hline$P_{g}$ & Grid Active power $(\mathrm{W})$ \\
\hline$Q_{g}$ & Grid Reactive power (vAR) \\
\hline$S^{0}$ & Solar irradiance $\left(\mathrm{W} / \mathrm{m}^{2}\right)$ \\
\hline$u_{p a}, u_{p b}, u_{p c}$ & In phase unit templates of phase voltages \\
\hline$u_{q a}, u_{q b}, u_{q c}$ & Quadrature unit templates of phase voltages \\
\hline$V_{a}, V_{b}, V_{c}$ & Phase voltage of utility grid (Volts) \\
\hline$v_{a b}, v_{b c}, v_{c a}$ & Line voltage of utility grid (Volts) \\
\hline$V_{d c}$ & DC link voltage (Volts) \\
\hline$V^{*} d c$ & Reference DC link voltage (Volts) \\
\hline$V_{M P P}$ & PV voltage at maximum power point (Ampere) \\
\hline$V_{p v}$ & PV output voltage (Volts) \\
\hline$V_{t}$ & Voltage at point of common coupling (Volts) \\
\hline
\end{tabular}




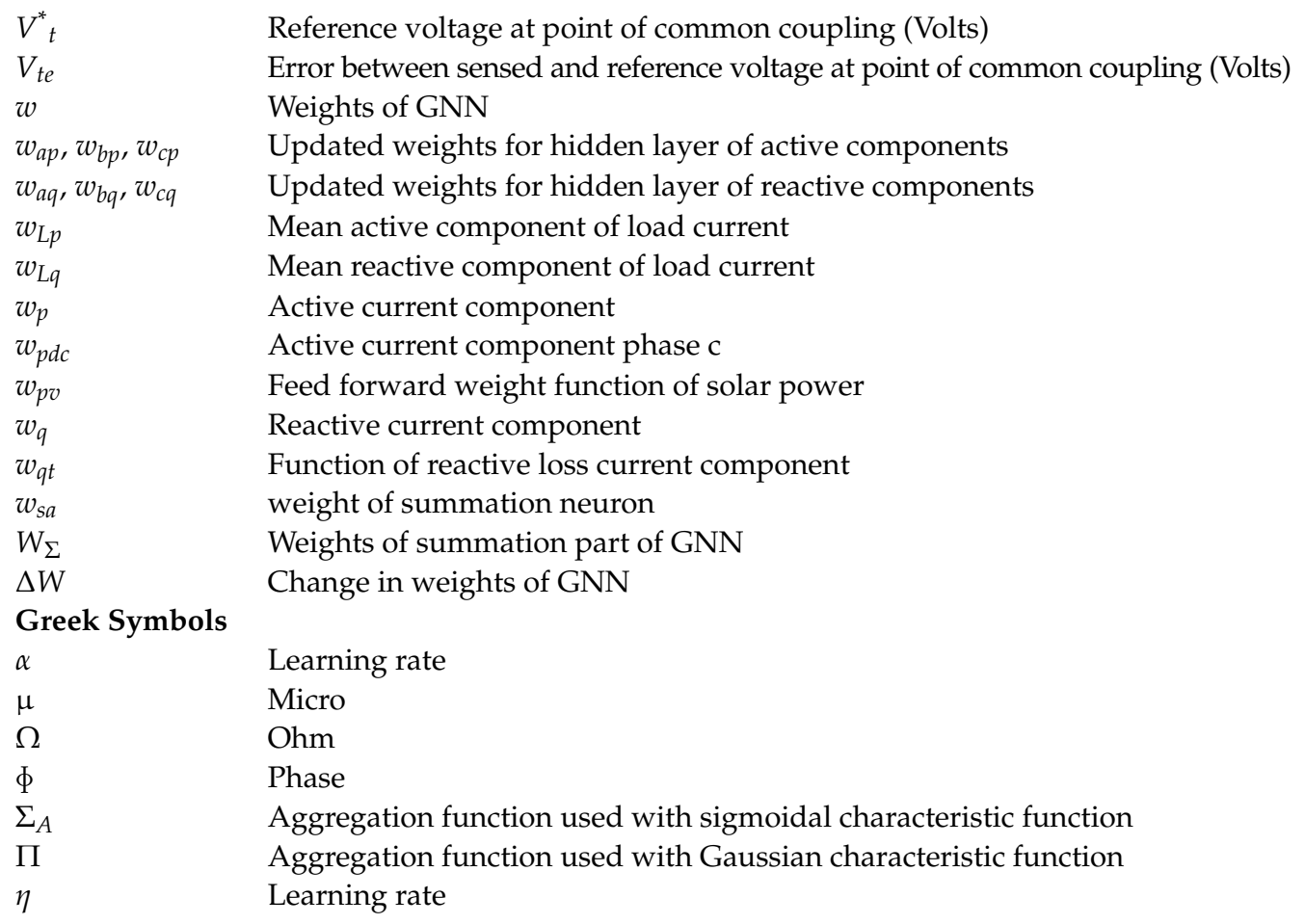

\section{References}

1. Hudson, R.; Heilscher, G. PV Grid Integration-System Management Issues and Utility Concerns. Energy Procedia 2012, 25, 82-92. [CrossRef]

2. IEEE. IEEE Recommended Practices and Requirement for Harmonic Control on Electric Power System; IEEE Std.: New York, NY, USA, 1992; p. 519.

3. Wu, T.-F.; Chang, C.-H.; Lin, L.-C.; Kuo, C.-L. Power loss comparison of single and two-stage grid-connected photovoltaic systems. IEEE Trans. Energy Convers. 2011, 26, 707-715. [CrossRef]

4. Arya, S.R.; Niwas, R.; Bhalla, K.K.; Singh, B.; Chandra, A.; Al-Haddad, K. Power quality improvement in isolated distributed power generating system using DSTATCOM. IEEE Trans. Ind. Appl. 2015, 51, 4766-4774. [CrossRef]

5. $\quad$ Singh, B.; Jayaprakash, P.; Kothari, D.P.; Chandra, A.; Al-Haddad, K. Comprehensive study of DSTATCOM configurations. IEEE Trans. Ind. Inform. 2014, 10, 854-870. [CrossRef]

6. Singh, B.; Solanki, J. A comparison of control algorithms for DSTATCOM. IEEE Trans. Ind. Electron. 2009, 56, 2738-2745. [CrossRef]

7. Kumar, C.; Mishra, M.K. A Multifunctional DSTATCOM Operating Under Stiff Source. IEEE Trans. Ind. Electron. 2013, 61, 3131-3136. [CrossRef]

8. Ahmad, M.T.; Kumar, N.; Singh, B. Generalised neural network-based control algorithm for DSTATCOM in distribution systems. IET Power Electron. 2017, 10, 1529-1538. [CrossRef]

9. Bag, A.; Subudhi, B.; Ray, P.K. A combined reinforcement learning and sliding mode control scheme for grid integration of a PV system. CSEE J. Power Energy Syst. 2019, 5, 498-506.

10. He, J.; Li, Y.W. Hybrid Voltage and Current Control Approach for DG-Grid Interfacing Converters with LCL filters. IEEE Trans. Ind. Electron. 2012, 60, 1797-1809. [CrossRef]

11. Tomar, A.; Mishra, S.; Bhende, C.N. Modified MISO DC-DC converter based PV water pumping system. In Proceedings of the 2016 IEEE 7th Power India International Conference (PIICON), Bikaner, India, 25-27 November 2016; Institute of Electrical and Electronics Engineers (IEEE): New York, NY, USA, 2016; pp. 1-6.

12. Alfaris, F.E.; Bhattacharya, S. Control and Real-Time Validation for Convertible Static Transmission Controller Enabled Dual Active Power Filters and PV Integration. IEEE Trans. Ind. Appl. 2019, 55, 4309-4320. [CrossRef]

13. Rengasamy, M.; Gangatharan, S.; Elavarasan, R.M.; Mihet-Popa, L. The Motivation for Incorporation of Microgrid Technology in Rooftop Solar Photovoltaic Deployment to Enhance Energy Economics. Sustainability 2020, 12, 10365. [CrossRef]

14. Jain, C.; Singh, B. A Three-Phase Grid Tied SPV System with Adaptive DC Link Voltage for CPI Voltage Variations. IEEE Trans. Sustain. Energy 2016, 7, 337-344. [CrossRef]

15. Agarwal, R.K.; Hussain, I.; Singh, B. Three-phase single-stage grid tied solar PV ECS using PLL-less fast CTF control technique. IET Power Electron. 2017, 10, 178-188. [CrossRef]

16. Singh, B.; Jain, C.; Goel, S.; Chandra, A.; Al-Haddad, K. A multifunctional grid-tied solar energy conversion system with ANF-based control approach. IEEE Trans. Ind. Appl. 2016, 52, 3663-3672. [CrossRef]

17. Vidal, H.; Rivera, M.; Wheeler, P.; Vicencio, N. The Analysis Performance of a Grid-Connected 8.2 kWp Photovoltaic System in the Patagonia Region. Sustainability 2020, 12, 9227. [CrossRef] 
18. Campanhol, L.B.G.; da Silva, S.A.O.; de Oliveira, A.A.; Bacon, V.D. Single-stage three-phase grid-tied PV system with universal filtering capability applied to DG systems and AC microgrids. IEEE Trans. Power Electron. 2017, 32, 9131-9142. [CrossRef]

19. Tomar, A.; Mishra, S. CMPVI-Based MIDO Scheme under SSE for Optimum Energy Balance and Reduced ROI. IEEE Trans. Sustain. Energy 2017, 9, 1318-1327. [CrossRef]

20. Huang, P.; Zhang, X.; Copertaro, B.; Saini, P.; Yan, D.; Wu, Y.; Chen, X. A Technical Review of Modeling Techniques for Urban Solar Mobility: Solar to Buildings, Vehicles, and Storage (S2BVS). Sustainability 2020, 12, 7035. [CrossRef]

21. Varma, R.K.; Rahman, S.A.; Vanderheide, T. New control of PV solar farm as STATCOM (PV-STATCOM) for increasing grid power transmission limits during night and day. IEEE Trans. Power Deliv. 2014, 30, 755-763. [CrossRef]

22. Hamid, M.I.; Jusoh, A.; Anwari, M. Photovoltaic plant with reduced output current harmonics using generation-side active power conditioner. IET Renew. Power Gener. 2014, 8, 817-826. [CrossRef]

23. Tomar, A.; Mishra, S.; Bhende, C.N. AOMH-MISO based PV-VCI irrigation system using ASCIM pump. IEEE Trans. Ind. Appl. 2018, 54, 4813-4824. [CrossRef]

24. Kannan, V.K.; Rengarajan, N. Investigating the performance of photovoltaic based DSTATCOM using I cos $\Phi$ algorithm. Int. J. Electr. Power Energy Syst. 2014, 54, 376-386. [CrossRef]

25. Panigrahi, R.; Mishra, S.K.; Srivastava, S.C.; Srivastava, A.K.; Schulz, N.N. Grid Integration of Small-Scale Photovoltaic Systems in Secondary Distribution Network-A Review. IEEE Trans. Ind. Appl. 2020, 56, 3178-3195. [CrossRef]

26. Mazumdar, J.; Harley, R.G. Recurrent neural networks trained with backpropagation through time algorithm to estimate nonlinear load harmonic currents. IEEE Trans. Ind. Electron. 2008, 55, 3484-3491. [CrossRef]

27. Mukundan, N.; Singh, Y.; Naqvi, S.B.Q.; Singh, B.; Pychadathil, J. Multi-Objective Solar Power Conversion System with MGI Control for Grid Integration at Adverse Operating Conditions. IEEE Trans. Sustain. Energy 2020, 11, 2901-2910.

28. Singh, B.; Arya, S.R. Back-Propagation Control Algorithm for Power Quality Improvement Using DSTATCOM. IEEE Trans. Ind. Electron. 2013, 61, 1204-1212. [CrossRef]

29. Jayachandran, J.; Sachithanandam, R.M. Neural Network-Based Control Algorithm for DSTATCOM Under Nonideal Source Voltage and Varying Load Conditions. Can. J. Electr. Comput. Eng. 2015, 38, 307-317. [CrossRef]

30. Janpong, S.; Areerak, K.L.; Areerak, K.N. A literature survey of neural network applications for shunt active power filters. World Acad. Sci. Eng. Technol. 2011, 5, 273-279.

31. Chaudhary, P.; Rizwan, M. QNBP NN-based I cos $\phi$ algorithm for PV systems integrated with LV/MV grid. Soft Comput. 2021, 25, 2599-2614. [CrossRef]

32. Chaudhary, P.; Rizwan, M. Intelligent approach-based hybrid control algorithm for integration of solar photovoltaic system in smart grid environment. IET Smart Grid 2019, 2, 445-454. [CrossRef]

33. Chaturvedi, D.K.; Malik, O.P.; Kalra, P.K. Generalised neuron-based adaptive power system stabiliser. IEEE Proc. Gener. Transm. Distrib. 2004, 151, 213-218. [CrossRef]

34. Chaturvedi, D.K. Soft Computing Techniques and Its Applications in Electrical Engineering; Springer: Berlin/Heidelberg, Germany, 2008.

35. Rizwan, M.; Jamil, M.; Kothari, D.P. Generalized Neural Network Approach for Global Solar Energy Estimation in India. IEEE Trans. Sustain. Energy 2012, 3, 576-584. [CrossRef]

36. Kulkarni, R.V.; Venayagamoorthy, G.K. Generalized neuron: Feedforward and recurrent architectures. Neural. Netw. 2009, 22, 1011-1017. [CrossRef]

37. Reisi, A.R.; Moradi, M.H.; Jamasb, S. Classification and comparison of maximum power point tracking techniques for photovoltaic system: A review. Renew. Sustain. Energy Rev. 2013, 19, 433-443. [CrossRef]

38. Almutairi, A.; Abo-Khalil, A.; Sayed, K.; Albagami, N. MPPT for a PV Grid-Connected System to Improve Efficiency under Partial Shading Conditions. Sustainability 2020, 12, 10310. [CrossRef]

39. Salah, C.B.; Ouali, M. Comparison of fuzzy logic and neural network in maximum power point tracker for PV systems. Electr. Power Syst. Res. 2011, 81, 43-50. [CrossRef]

40. Williams, R.J. Training recurrent networks using the extended Kalman filter. In Proceedings of the 1992 IJCNN International Joint Conference on Neural Networks, Baltimore, MD, USA, 7-11 June 1992; IEEE: New York, NY, USA, 2003; pp. $241-246$.

41. de Oliveira, M.A. An application of neural networks trained with kalman filter variants (ekf and ukf) to heteroscedastic time series forecasting. Appl. Math. Sci. 2012, 6, 3675-3686.

42. Bishop, G.; Welch, G. An introduction to the kalman filter. Proc. SIGGRAPH Course 2001, 8, 23175-27599.

43. Chaudhary, P.; Rizwan, M. Hybrid control approach for PV/FC fed voltage source converter tied to grid. Int. J. Hydrogen Energy 2018, 43, 6851-6866. [CrossRef] 